\title{
Effect of Gold Dispersion on the Photocatalytic Activity of Mesoporous Titania for the Vapor-Phase Oxidation of Acetone
}

\author{
S. V. Awate, A. A. Belhekar, S. V. Bhagwat, R. Kumar, and N. M. Gupta \\ Catalysis Division, National Chemical Laboratory, Dr. Homi Bhabha Road, Pune 411008, India
}

Correspondence should be addressed to N. M. Gupta,nm.gupta@ncl.res.in

Received 30 September 2007; Accepted 26 November 2007

Recommended by Vincenzo Augugliaro

\begin{abstract}
Mesostructured titanium dioxide photocatalyst, having uniform crystallite size $(6-12 \mathrm{~nm})$ and average pore diameter of $\sim 4.2 \mathrm{~nm}$, was synthesized by using a low-temperature nonsurfactant hydrothermal route, employing tartaric acid as a templating agent. Gold additions from 0.5 to $2 \mathrm{wt} \%$ were incorporated, either during the hydrothermal process or by postsynthesis wet impregnation. Compared to the impregnation-prepared samples, the samples synthesized hydrothermally contained smaller-size $(\leq 1 \mathrm{~nm})$ gold clusters occluded in the pores of the host matrix. Whereas $\mathrm{CO}_{2}$ and $\mathrm{H}_{2} \mathrm{O}$ were the main reaction products in UV-assisted vaporphase oxidation of acetone using these catalysts, $\mathrm{C}_{2} \mathrm{H}_{6}$ and $\mathrm{HCO}_{2} \mathrm{CH}_{3}$ were also produced for higher acetone concentrations in air. The conversion of acetone was found to increase with decrease in the size of both $\mathrm{TiO}_{2}$ and gold particles. In situ IR spectroscopy revealed that titania and gold particles serve as independent adsorption and reaction sites for acetone and oxygen molecules. Acetone molecules adsorb exclusively at $\mathrm{TiO}_{2}$ surface, giving rise to a strongly adsorbed (condensed) state as well as to the formation of formate- and methyl formate-type surface species. Hydroxyl groups at titania surface participate directly in these adsorption steps. Nanosize gold particles, on the other hand, were primarily responsible for the adsorption and activation of oxygen molecules. Mechanistic aspects of the photochemical processes are discussed on the basis of these observations.
\end{abstract}

Copyright (c) 2008 S. V. Awate et al. This is an open access article distributed under the Creative Commons Attribution License, which permits unrestricted use, distribution, and reproduction in any medium, provided the original work is properly cited.

\section{INTRODUCTION}

Concerted research has been devoted to oxidative degradation of volatile organic contaminants via photocatalytic route, with a view to find a viable solution to environmental pollution control [1-3]. Nevertheless, the low quantum yield and poor stability of presently available photocatalytic materials have posed limitations on the large-scale application of the above-mentioned process. These deficiencies arise mainly due to the following reasons: (i) dependence on UV radiation due to large band gap, (ii) a low rate of electron transfer to reactant molecules including oxygen, and (iii) a high rate of recombination of electron-hole pair resulting in low quantum yields. Various approaches have been attempted to enhance the efficiency of photocatalytic materials, either by bringing out certain structural and morphological modifications or by incorporation of certain cocatalysts. In the case of widely studied titanium dioxide photocatalyst, following general strategies have been adopted: (i) morphological changes in bulk $\mathrm{TiO}_{2}[1-8]$, (ii) doping of $\mathrm{TiO}_{2}$ with a group VIII metal or a noble metal to increase the lifetime of electron-hole pair and extending the light absorption to visible region, [9-13], (iii) incorporation of $\mathrm{TiO}_{2}$ in certain mesoporous materials in order to increase the exposed area [14-17], and (iv) chemical substitution at Ti or O sites, so as to modify the band characteristics and to shift the absorbance toward visible region [18-21]. In spite of these recent developments, detailed knowledge on the precise role of morphological properties of $\mathrm{TiO}_{2}$, and also that of a metal cocatalyst, still eludes us.

In the recent studies reported by Bhattacharya et al. $[14,15]$, we demonstrated that the nanosize $\mathrm{TiO}_{2}$ clusters dispersed in mesoporous MCM-41 silica matrix exhibited a microenvironment that was different from that of the bulk titania. The photocatalytic properties of these samples were found to exhibit direct relationship with the number of chemisorption sites rather than to the changes in electronic properties [15]. In the present study, we have adopted a hydrothermal route for the preparation of bulk titanium dioxide samples, comprised of nanosize crystallites that exhibit a mesoporous character. Gold additions from 0.5 to $2 \mathrm{wt} \%$ of gold were doped in these samples by adopting 
two different approaches, namely inclusion of $\mathrm{Au}$ during the hydrothermal step or alternatively its dispersion over assynthesized mesoporous $\mathrm{TiO}_{2}$ by insipient wet impregnation. The samples were characterized for their structural and morphological properties by using the techniques of powder X-ray diffraction (XRD), diffuse reflectance UV-visible spectroscopy (DR UV-Vis), thermal analysis (TG/DTA), $\mathrm{N}_{2}$ adsorption, and transmission electron microscopy (TEM). Vapor-phase photo-oxidation of acetone was employed as a representative and the reaction was carried out both under visible and UV irradiations. In situ diffuse reflectance infrared Fourier-transform (DRIFT) spectroscopy helped in probing the surface transient studies formed during the interaction of acetone alone or in the presence of oxygen. The role of these transient species in the overall photocatalytic process is elucidated on the basis of these experimental results.

\section{EXPERIMENTAL}

\subsection{Sample preparation}

The sample of mesoporous $\mathrm{TiO}_{2}$ was synthesized by following a low-temperature nonsurfactant hydrothermal route, using tartaric acid as structure directing agent. In this method, about $10 \mathrm{~mL}$ of $\mathrm{Ti}(\mathrm{IV})$ isopropoxide (Aldrich Chemie, Steinheim, Germany) was added slowly to a mixture of $1 \mathrm{~N} \mathrm{HCl}$ and tartaric acid $(3.6 \mathrm{~g})$ under stirring, with the $\mathrm{HCl} /$ alkoxide ratio being $\sim 1$. The $\mathrm{pH}$ of the resultant mix was $\sim 5$. After complete hydrolysis of the alkoxide, the mixture was transferred into a Teflon-lined autoclave and heated at $403 \mathrm{~K}$ for 3 days followed by cooling to room temperature. The mass was centrifuged and washed several times with distilled water. The white precipitate thus achieved was dried at $373 \mathrm{~K}$ for $4-5$ hours and then calcined at $623 \mathrm{~K}$ for 3 hours to get a sample denoted as T1.

The samples of mesoporous $\mathrm{TiO}_{2}$ containing 0.5 to $2 \mathrm{wt} \%$ of gold were synthesized by following two different methods. In method I, a required amount of chloroauric acid $\left(\mathrm{HAuCl}_{4}\right.$, Loba Chemie, Mumbai, India) was added to the mixture of alkoxide and $\mathrm{HCl}$ during the hydrolysis step, as described above. After drying at $373 \mathrm{~K}$, the samples were calcined at different temperatures in the range of 525-773 K and are denoted as H1-H6 in Table 1. In method II, hydrothermally prepared titania powder (sample T1) was impregnated with varying amounts of aqueous chloroauric acid solution, followed by drying and calcination at an optimized temperature of $623 \mathrm{~K}$ (samples denoted as I1-I3). For some comparative experiments, a sample of pure gold powder was prepared by hydrazine reduction of aqueous chloroauric acid solution, followed by filtration, drying at $370 \mathrm{~K}$, and then heating under vacuum ( $520 \mathrm{~K}$ for 3 hours, $750 \mathrm{~K}$ for 2 hours).

\subsection{Characterization}

The gold content in the synthesized samples was estimated by energy dispersive analysis of X-rays (EDAX), using a PHOENIX stereoscan-440 accessory attached to a scanning electron microscope (Leica, cambridge, UK). An $\mathrm{Au}-\mathrm{Cu}$ metal coupon was used for calibration purposes. The gold concentration in the samples, added initially and the analyzed value in the final product, is given in Table 1.

Powder XRD patterns were recorded in the wide-angle range on Rigaku, Miniflex (D Max III VC) XRD machine $\left(\mathrm{CuK}_{\propto}\right.$ radiation) operated at $30 \mathrm{kV}$ and $15 \mathrm{~mA}$. Low-angle powder X-ray diffraction (LAXRD) patterns were recorded over the scan range $2 \theta=1.5$ to $5^{\circ}$ using a Philips X'Pert Pro (M/S Panalytical) diffractometer using $\mathrm{CuK}_{\propto}$ radiation $(\lambda=$ $1.5406 \AA$ ) operated at $40 \mathrm{kV}$ and $30 \mathrm{~mA}$.

TEM images were obtained on a JEOL-2010 CX microscope. The information about BET surface area and pore characteristics of different samples was derived from lowtemperature nitrogen adsorption isotherms, recorded on a Quantachrome NOVA 1200 equipment, after pretreatment at $573 \mathrm{~K}$ under vacuum. The $\mathrm{BJH}$ formulation was employed to obtain the pore-size distribution data. The samples were further characterized by using DR UV-Vis spectroscopy (LAMBDA 650 spectrophotometer, Perkin-Elmer, Shelton, USA). About $3 \mathrm{wt} \%$ of a sample was mixed in barium sulfate for these absorbance measurements. The simultaneous TG/DTA scans were recorded in argon atmosphere for a representative sample $\mathrm{H} 1$, so as to monitor various steps involved in sample synthesis.

\subsection{Catalytic activity}

The experiments on photocatalytic oxidation of acetone were conducted both under UV radiation and also under visible light. A $400 \mathrm{~W}$ mercury vapor lamp $(225-400 \mathrm{~nm}$, peak at $365 \mathrm{~nm}$ ) was employed for UV irradiation and a $500 \mathrm{~W}$ halogen lamp served as a visible light source. Both light sources were housed in water cooled jackets to cut off infrared radiation. An amount of $25 \mathrm{mg}$ of a sample was charged in a pyrex glass photoreactor ( $100 \mathrm{~mL}$ capacity) for activity measurement where acetone vapor mixed in air (1-25 mol\%) was introduced after a brief pumping. The experiments were conducted at room temperature under static condition, and the reaction products formed as a function of radiation exposure were analyzed on a gas chromatograph (Shimadzu model-R15A, Porapaq-Q column, TCD detector). Qualitative analysis was also conducted on some of the representative samples using a GC-MS (Shimadzu model-R-15A) with a view to establish the identity of the reaction products formed.

\subsection{IR study of transient surface species}

The IR spectra of surface species formed during exposure of $\mathrm{TiO}_{2}$ and $\mathrm{Au} / \mathrm{TiO}_{2}$ to acetone were recorded in DRIFT mode using a Shimadzu SSU-8000 spectrophotometer. About $14 \mathrm{mg}$ catalyst powder packed in the sample holder was activated in situ at $625 \mathrm{~K}$ for $\sim 3$ hours in a flowing stream $\left(40 \mathrm{~mL} \mathrm{~min}^{-1}\right.$ ) of pure $\mathrm{N}_{2}$, followed by cooling to room temperature and recording of a background spectrum. The sample, maintained under nitrogen flow, was then exposed to several successive pulses of either pure acetone vapor or acetone $(10 \mathrm{~mol} \%)+$ air, and the IR spectra were recorded at each stage. The effect of raising the sample temperature subsequent to saturation coverage was also monitored. 
Table 1: Physical properties of $\mathrm{TiO}_{2}$ and $\mathrm{Au} / \mathrm{TiO}_{2}$ samples.

\begin{tabular}{|c|c|c|c|c|c|c|c|}
\hline \multirow[t]{2}{*}{ Sample } & \multirow{2}{*}{$\begin{array}{l}\text { Calcination } \\
\text { Temp. }(\mathrm{K})\end{array}$} & \multicolumn{2}{|c|}{ Au content (wt $\%)$} & \multirow{2}{*}{$\begin{array}{l}\text { Surface area } \\
\left(\mathrm{m}^{2} \mathrm{~g}^{-1}\right)\end{array}$} & \multirow{2}{*}{$\begin{array}{l}\text { Average crys- } \\
\text { tallite size }{ }^{(\mathrm{d})} \\
(\mathrm{nm})\end{array}$} & \multirow{2}{*}{$\begin{array}{l}\text { Average gold } \\
\text { particle size }{ }^{(\mathrm{e})} \\
(\mathrm{nm})\end{array}$} & \multirow{2}{*}{$\begin{array}{l}\text { Average pore } \\
\text { diameter }^{(\mathrm{f})} \\
(\mathrm{nm})\end{array}$} \\
\hline & & Initial & Final & & & & \\
\hline $\mathrm{T} 1^{(\mathrm{a})}$ & 623 & - & & 109 & 9.6 & - & 4.2 \\
\hline $\mathrm{H} 1^{(\mathrm{b})}$ & 375 & 1.0 & 0.6 & - & - & - & - \\
\hline $\mathrm{H} 2^{(\mathrm{b})}$ & 523 & 1.0 & 0.6 & 214.4 & 5.2 & $\sim 1.0$ & $3.5,2.4$ \\
\hline $\mathrm{H} 3^{(\mathrm{b})}$ & 623 & 1.0 & 0.6 & 157.0 & 4.4 & 1.0 & $3.3,1.6$ \\
\hline $\mathrm{H} 4^{(\mathrm{b})}$ & 773 & 1.0 & 0.6 & - & 10.8 & - & - \\
\hline $\mathrm{H} 5^{(\mathrm{b})}$ & 623 & 1.5 & 0.8 & 66.1 & 11.3 & 5.7 & 3.8 \\
\hline $\mathrm{H} 6^{(\mathrm{b})}$ & 623 & 2.0 & 1.3 & 65.0 & 8.7 & - & - \\
\hline $\mathrm{I} 1^{(\mathrm{c})}$ & 623 & 1.0 & 1.1 & 74.7 & 7.1 & 7.5 & 4.7 \\
\hline $\mathrm{I} 2^{(\mathrm{c})}$ & 623 & 1.5 & 1.7 & 35.7 & 7.0 & - & 4.5 \\
\hline $\mathrm{I} 3^{(\mathrm{c})}$ & 623 & 2.0 & 2.1 & 39.4 & 7.0 & 9.0 & 4.5 \\
\hline
\end{tabular}

(a) $\mathrm{TiO}_{2}$ sample prepared by hydrothermal route.

(b) $\mathrm{Au} / \mathrm{TiO}_{2}$ with gold incorporated during hydrothermal process.

(c) $\mathrm{Au} / \mathrm{TiO}_{2}$ with gold dispersed over sample $\mathrm{T} 1$ by impregnation.

(d) From XRD data using Scherrer's equation.

(e) From TEM results.

${ }^{(f)}$ From $\mathrm{N}_{2}$ adsorption data.

200 scans were coadded at a resolution of $4 \mathrm{~cm}^{-1}$ and the background spectrum of blank $\mathrm{TiO}_{2}$ was compensated for recording of each plot.

\section{RESULTS AND DISCUSSION}

\subsection{Morphological features}

The notations and morphological properties of different samples are listed in Table 1. Figures $1(\mathrm{a})-1$ (c) provide TEM images of representative mesoporous $\mathrm{TiO}_{2}$ and $\mathrm{Au} / \mathrm{TiO}_{2}$ samples. Comparative pore-size distribution in some of the samples, as measured by $\mathrm{N}_{2}$-adsorption, is presented in Figures 2(a)-2(d). As seen in these data, the surface area, crystallite shape and size, and the pore characteristics of different samples depend considerably on the amount of gold present and the mode of its doping. The gold-free $\mathrm{TiO}_{2}$ sample (T1), prepared by hydrothermal route and calcined at $623 \mathrm{~K}$, is comprised of almost round shape crystallites, size varying from 6 to $12 \mathrm{~nm}$ and the majority being around $7.5 \mathrm{~nm}$ in cross-sectional diameter (Figure 1(a)). The pore-size distribution in this sample falls in a narrow range ( 3 to $5 \mathrm{~nm}$ ), with the average pore-diameter being $\sim 4.2 \mathrm{~nm}$ (Figure 2(a), Table 1). The inclusion of a small amount of gold ( $1 \mathrm{wt} \%$ ) during hydrothermal synthesis resulted in more uniform and much smaller $(1.5$ to $3 \mathrm{~nm})$ crystallites, as can be seen in Figure 1(b). The dark spots of high scattering contrast in the middle of these crystallites may be related to the presence of gold particles entrapped in the mesopores, the size of which is estimated at $\leq 1 \mathrm{~nm}$. In addition to almost sphericalshape $\mathrm{TiO}_{2}$ crystallites seen in Figure 1(b), the presence of titania nanotubes (cross-sectional diameter of around $6 \mathrm{~nm}$ and length varying from 15 to $70 \mathrm{~nm}$ ) was also noticed in few TEM micrographs. No gold particles were, however, noticeable in the vicinity of these nanotubes.
The size of the gold particles increased considerably with the increase of gold loading and also when the samples were prepared by using method II. For instance, the TEM micrograph of sample $\mathrm{H} 5$ showed the presence of gold crystallites of size 3-8 nm, dispersed prominently at the extraneous host surface. The size of the gold crystallites was found to increase further in the samples synthesized by impregnation. Figure 1(c) exhibits the typical TEM micrograph of sample I1, containing $1 \mathrm{wt} \%$ of Au. Gold particles, having size in a wide range of 3 to $15 \mathrm{~nm}$, are seen clearly in this picture.

The $\mathrm{N}_{2}$-adsorption results reveal that the pore characteristics are affected considerably by the amount of gold present in a sample and the method of preparation. Thus, sample T1 consisted of uniform-size pores of average size $4.2 \mathrm{~nm}$ (Figure 2(a)), while samples $\mathrm{H} 2$ and $\mathrm{H} 3$ reveal the presence of a bimodal pore system (Figures 2(b), 2(c)). In the case of $\mathrm{H} 2$, the average size of mesopores is found to be $\sim 3.5 \mathrm{~nm}$ instead of $4.2 \mathrm{~nm}$ and an equal number of pores in size range 1 to $3 \mathrm{~nm}$ are formed as a result of gold inclusion (Figure 2(b)). Increase in calcination temperature to $623 \mathrm{~K}$ for sample $\mathrm{H} 3$ resulted in further decrease in the size and number of larger-size pores whereas those of the smallersize pores increased considerably (Figure 2(c)). For the samples containing higher loading of $\mathrm{Au}$ and also in case of the samples prepared by method II, the number of smaller-size pores is very small while the larger-size pores are affected only marginally. A typical pore-size distribution pattern for sample I3 is shown in Figure 2(d).

The results described above suggest that for the low loadings $(\leq 1 \% \mathrm{Au})$, gold crystallites are very small in size $(\leq 1 \mathrm{~nm})$ and are located preferably within the mesopores of titania causing constriction, as is also indicated in the TEM picture of Figure 1(b). For the higher loadings and in the case when samples were synthesized by impregnation, the size of the gold particles increases considerably, and resultantly they 


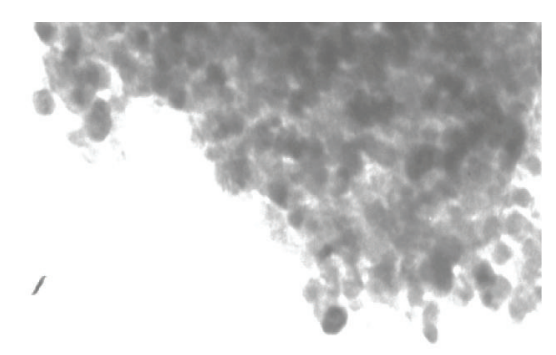

$\underline{50 \mathrm{~nm}}$

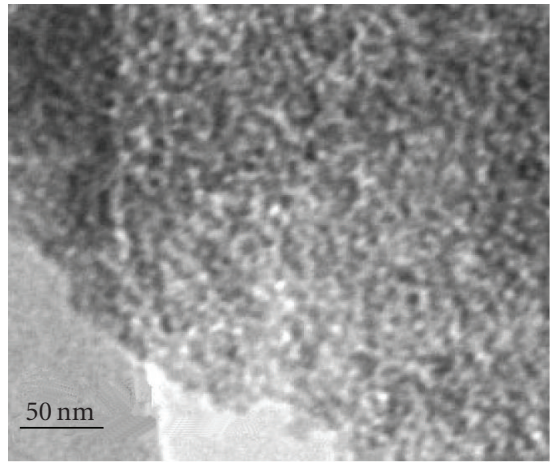

(b)

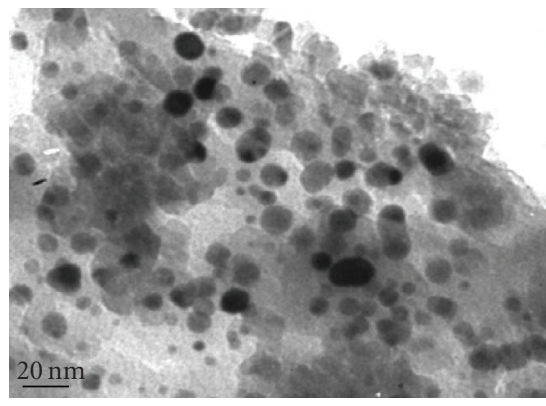

(c)

FIGURE 1: TEM micrographs of mesostructured titania and $\mathrm{Au} / \mathrm{TiO}_{2}$ samples: (a) mesoporous $\mathrm{TiO}_{2}(\mathrm{~T} 1),(\mathrm{b}) \mathrm{Au} / \mathrm{TiO} \mathrm{O}_{2}(\mathrm{H} 3)$, and (c) sample I1.

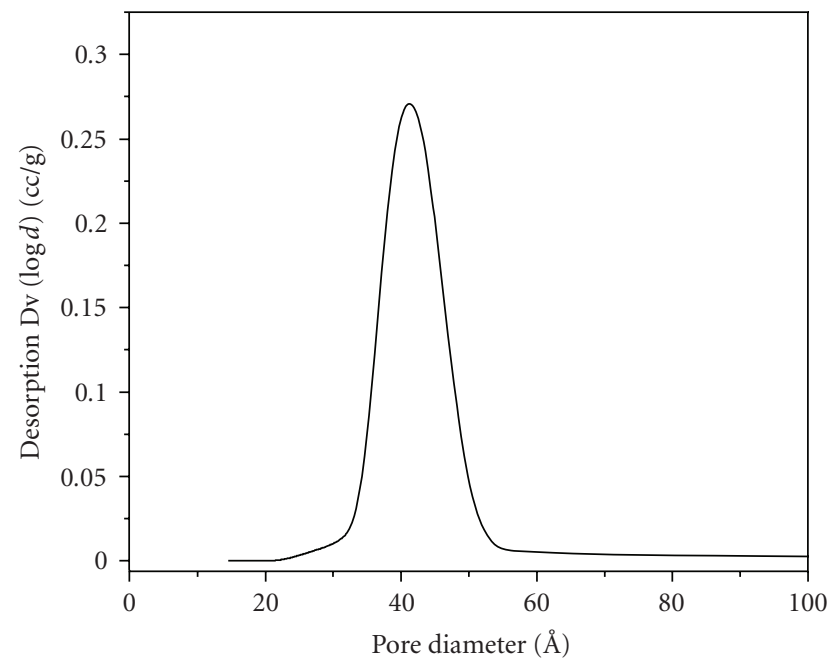

(a)

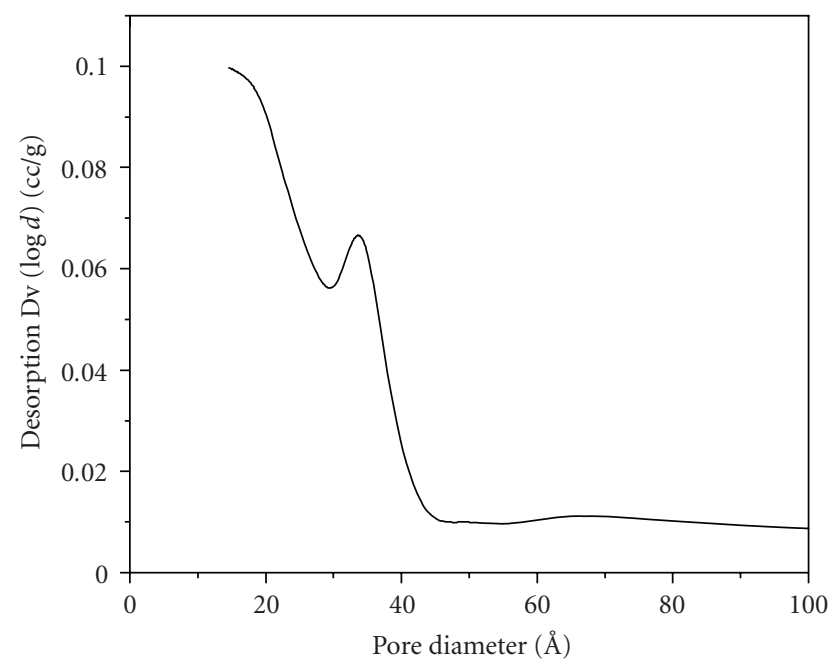

(c)

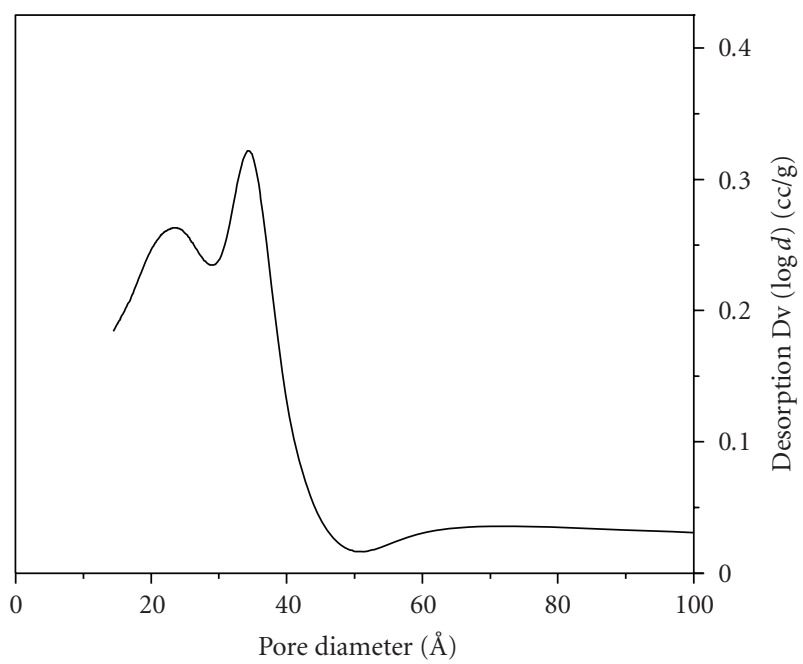

(b)

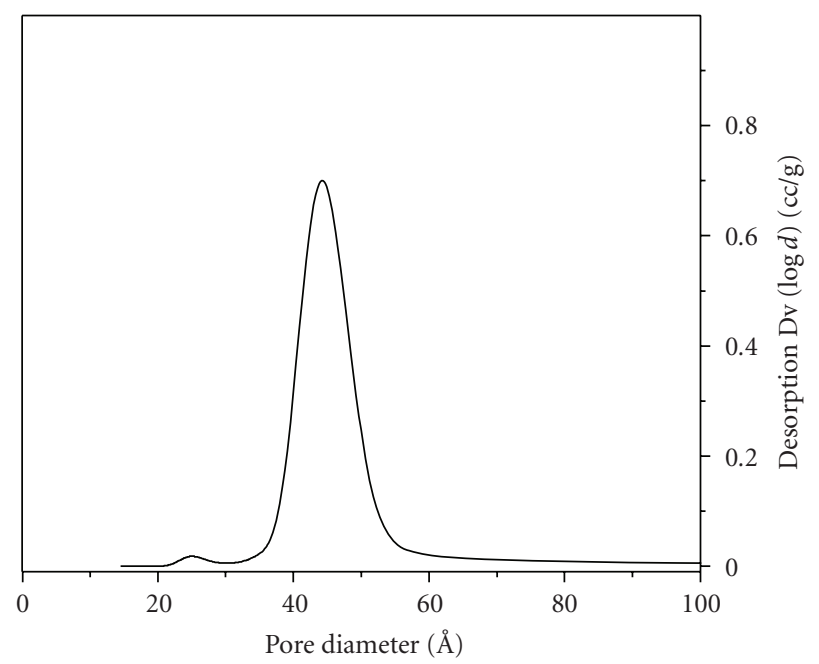

(d)

Figure 2: Pore-size distribution profiles in mesoporous $\mathrm{TiO}_{2}$ and $\mathrm{Au} / \mathrm{TiO}_{2}$ samples: (a) $\mathrm{T} 1$, (b) $\mathrm{H} 2$, (c) $\mathrm{H} 3$, and (d) I3. 
exist mainly at the extraneous surface of host titania matrix (Figure 1(c)). This may lead to complete or partial blockage of some of the pores while leaving others unaffected, as is indicated in the pore-size distribution data of Figure 2(d).

Our results also show that by adopting a nonsurfactant approach [22], and by using a small molecule such as tartaric acid for template, it is possible to synthesize physically stable, very small and uniform-size (6-12 nm) titania crystallites, as compared to several earlier attempts in this direction that employed large-size templating agents, such as dodecylamin and poly ethylene oxide (PEO) and obtained a material having a low surface area and a larger crystallite size [23-25].

\subsection{Powder XRD}

Curves (a)-(e) in Figure 3(a) show the wide-angle powder XRD patterns of gold-containing $\mathrm{TiO}_{2}$ samples prepared by hydrothermal process followed by calcination under different conditions. Curve (f) in this figure is for corresponding goldfree titania sample T1. The prominent XRD lines appearing in curve (f) at $2 \theta$ values of $25.2,36.8,37.8,48.1,54.0,55.1$, and 62.7 degrees are the characteristic reflections of anatasephase $\mathrm{TiO}_{2}$ (JCPDS card 21-2172). A considerable increase in the line widths, particularly in curves $(\mathrm{a})-(\mathrm{c})$, is a feature arising due to decrease in particle size. The size of crystallites in different samples, as calculated from the width of $\mathrm{I}_{100}$ reflection by using Scherrer's equation, is given in Table 1. The presence of small amount of gold in our samples is indicated by a weak and broad XRD line appearing at $44.5^{\circ}$ $(\mathrm{d}=2.04)$ in curves $(\mathrm{a})-(\mathrm{e})$, revealing again the small size of Au crystallites. The X-ray diffraction patterns of samples I1-I3 were found to be almost similar to those of sample T1, with no measurable change in $2 \theta$ value or in the line width (Figure 3(b)). A marginal change was, however, observed in the relative intensity of two main reflections appearing at $2 \theta$ values of 25.2 and 48.2 degrees.

Figure 4 presents the low-angle XRD patterns of some of the hydrothermally synthesized samples. Data in this figure reveal that an appropriate thermal treatment is vital for preparing a suitable mesoporous $\mathrm{TiO}_{2}$ matrix. Figure 4 shows that no long-range mesoporous structure is formed at the stage of hydrothermal treatment (curve (a)) and also after subsequent calcination at a low temperature $(\sim 523 \mathrm{~K}$ ) (curve (b)). This can be attributed to incomplete removal of condensed moieties from the pores. A well-ordered mesoporous structure is observed only on calcination of the sample at $623 \mathrm{~K}$, as is reflected in the broad peak appearing at $\sim 1.8^{\circ}$ in curve (c) of Figure 4. A similar low-angle XRD pattern has been reported earlier for mesoporous titania [1]. At the same time, the break down of this ordered structure is observed for the further increase in calcination temperature, as is evident from the LAXRD pattern of sample H4, shown in curve (d) of Figure 4.

\subsection{TG/DTA studies}

TG/DTA curves in Figure 5 correspond to as-synthesized Au $(1 \%) / \mathrm{TiO}_{2}$ (sample $\mathrm{H} 1$ ), where after hydrothermal treatment the sample was subjected to drying in air at $375 \mathrm{~K}$ with- out further calcination. The differential TG scan (curve (b)) indicates weight loss in two major steps: at $400 \mathrm{~K}$ due to release of adsorbed water and at $510 \mathrm{~K}$ because of the decomposition of tartaric acid used as a templating agent. These assignments were validated by independently recording the thermal data for pure tartaric acid. Closely spaced dual endotherms appearing at $510 \mathrm{~K}$ and $525 \mathrm{~K}$ in DTA plot (curve (c)) suggest that the decomposition of tartaric acid and the release of the reaction products may occur in two different steps. A small TG peak appearing at $645 \mathrm{~K}$ (curve (b)) and the corresponding endotherms in curve (c) are related to conversion of gold to its metallic state.

The data of thermal analyses presented above in conjunction with low-angle XRD results of Figure 4 help us to demonstrate that the removal of tartaric acid at an appropriate temperature subsequent to hydrothermal treatment and drying of gel is a vital step for preparing mesoporous titania. Thus, no $\mathrm{N}_{2}$ adsorption or mesoporosity are observed in sample H1, dried at $375 \mathrm{~K}$ (Table 1) but subjected to no further calcination. Removal of tartaric acid begins at $470 \mathrm{~K}$ but remains incomplete on calcination at $523 \mathrm{~K}$ (Figure 5, curve (b)), and the sample $\mathrm{H} 2$ therefore exhibits nitrogen adsorption corresponding to mesoporous materials (Figure 2(b)), but no long-range mesoporous network is formed yet (Figure 4, curve (b)). Calcination at $623 \mathrm{~K}$ enables complete removal of tartaric acid and thus gives rise to a long-range mesoporous network (Figure 4, curve (c)). Further, calcination at $750 \mathrm{~K}$ or above resulted in the collapse of porous titania network, as is revealed in curve (d) of Figure 4, recorded for sample $\mathrm{H} 4$.

\subsection{DR UV-Vis spectra}

The presence of gold was found to have a considerable influence on the DR UV-Vis spectrum of $\mathrm{TiO}_{2}$, depending upon its amount and the method of sample preparation. Figures 6(a) and 6(b) exhibit these data for $\mathrm{Au} / \mathrm{TiO}_{2}$ samples synthesized by using methods I and II, respectively. Comparative data on sample $\mathrm{T} 1$ are given in curve (e) of Figure 6(a). As is noticed in Figure 6(a), absorbance in UV region increases considerably in case of $\mathrm{Au} / \mathrm{TiO}_{2}$ samples synthesized by method I, as compared to sample T1 (curve (e)). The intensity of this absorbance band, however, decreases progressively on calcination at higher temperatures (curve (c)), and also for higher loadings of Au (curve (d)). We also observe a broad absorption band in the entire visible region of spectrum in the case of samples containing gold (cf. Figure 6(a), curve (e)). The intensity of the visible region absorbance $(400-800 \mathrm{~nm})$ is also found to decrease marginally with the increasing gold content.

The intensity of UV-region absorbance band for samples I1-I3, synthesized by impregnation, was found to be almost similar to that of T1. However, the visible region absorbance was much higher for these samples, which may be attributed to the absorbance by the gold crystallites existing at the external surface (Figure 6(b)).

The results presented above thus clearly reveal a direct relationship between the intensity of absorbance bands, both 


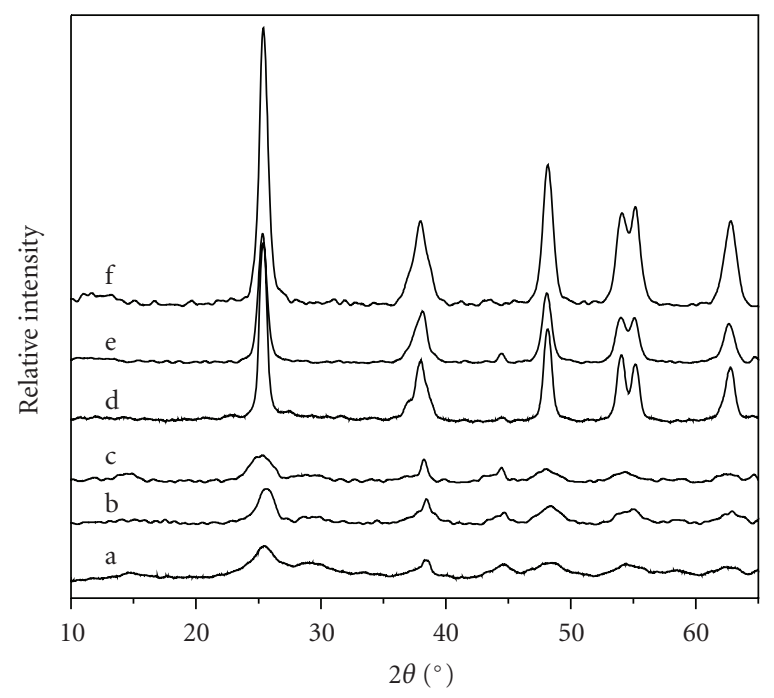

(a)

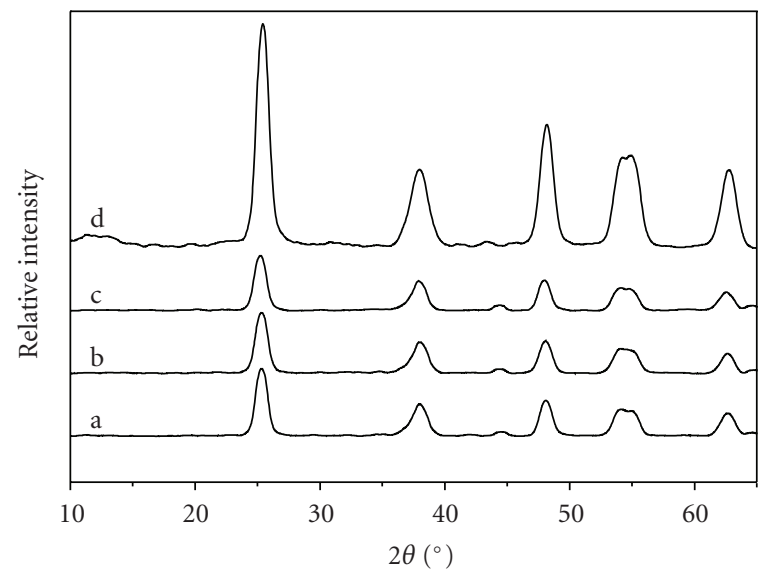

(b)

FIGURe 3: (a) Wide-angle powder XRD patterns of mesoporous $\mathrm{TiO}_{2}$ and hydrothermally synthesized $\mathrm{Au} / \mathrm{TiO}$, samples: (a) $\mathrm{H} 1$, (b) $\mathrm{H}$ 2, (c) $\mathrm{H} 3$, (d) $\mathrm{H} 4$, (e) $\mathrm{H} 5$, and (f) T1. (b) Comparative wide-angle powder XRD patterns of impregnation-prepared $\mathrm{Au} / \mathrm{TiO} \mathrm{O}_{2}$ and gold-free TiO samples: (a) I1, (b) I2, (c) I3, and (d) T1.

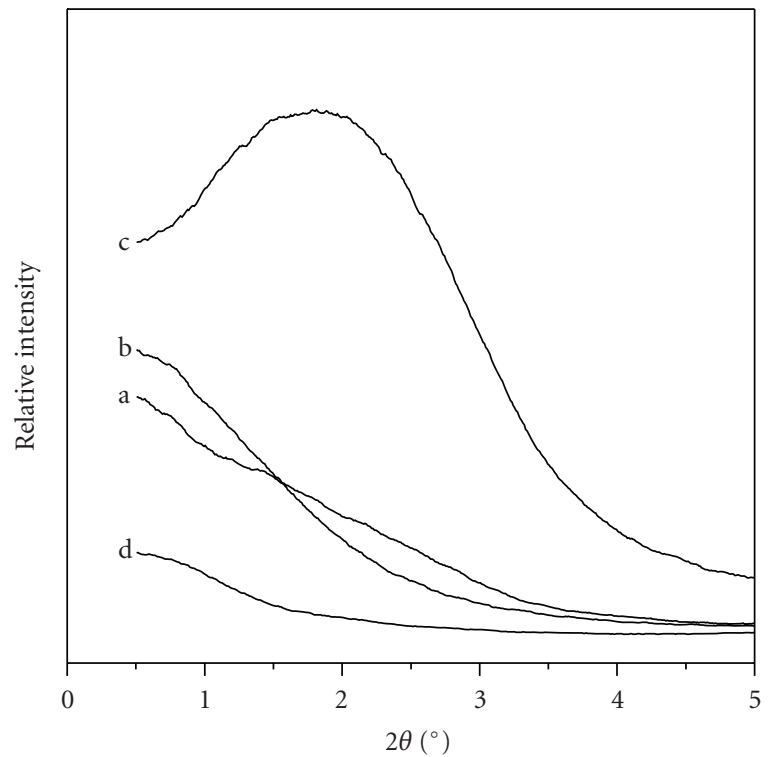

FIgURE 4: Low-angle powder XRD patterns of mesoporous $\mathrm{Au} / \mathrm{TiO}_{2}$ samples synthesized by hydrothermal route and calcined at different temperatures: (a) H1, (b) H2, (c) H3, and (d) H4.

in UV and visible regions, and the crystallite size of titania as well as that of the dispersed gold. In both cases, the higher the crystallite size is, the lower the value of the absorbance will be. The visible region absorbance in Figures 6(a), 6(b) is a characteristic feature associated with the nanostructured gold where the weak and broad band appearing at 550$600 \mathrm{~nm}$ is a well-reported phenomenon arising due to plasmon resonance [26].

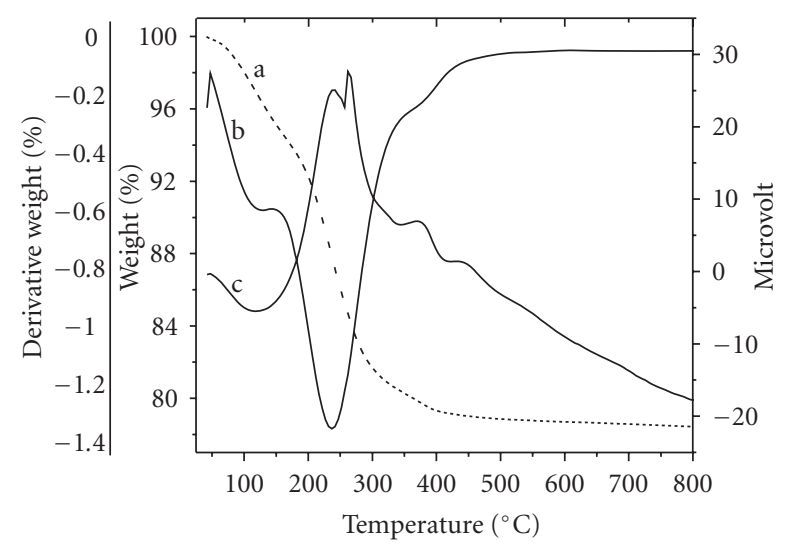

FIGURE 5: Thermal analysis data on hydrothermally prepared uncalcined $\mathrm{Au} / \mathrm{TiO}_{2}$ gel (sample H1): (a) TG, (b) DTG, and (c) DTA.

\subsection{Photocatalytic activity}

When acetone vapor + air were fed to the reactor at room temperature and in the absence of radiation, no reaction occurred over mesoporous $\mathrm{TiO}_{2}$ (sample T1) as well as over $\mathrm{Au} / \mathrm{TiO}_{2}$ samples prepared by the two methods described above. Similarly, no products were formed in the presence of visible light.

The reaction products formed during photo-oxidation of acetone under UV irradiation were mainly carbon dioxide and water. Small quantities of ethane and methyl formate ( $\mathrm{H}-\mathrm{COO}-\mathrm{CH}_{3}$, IUPAC name methyl methanoate) were produced only for higher concentrations of acetone in air. The catalytic activity and yield of these products depended on various factors, such as radiation dose, concentration of 


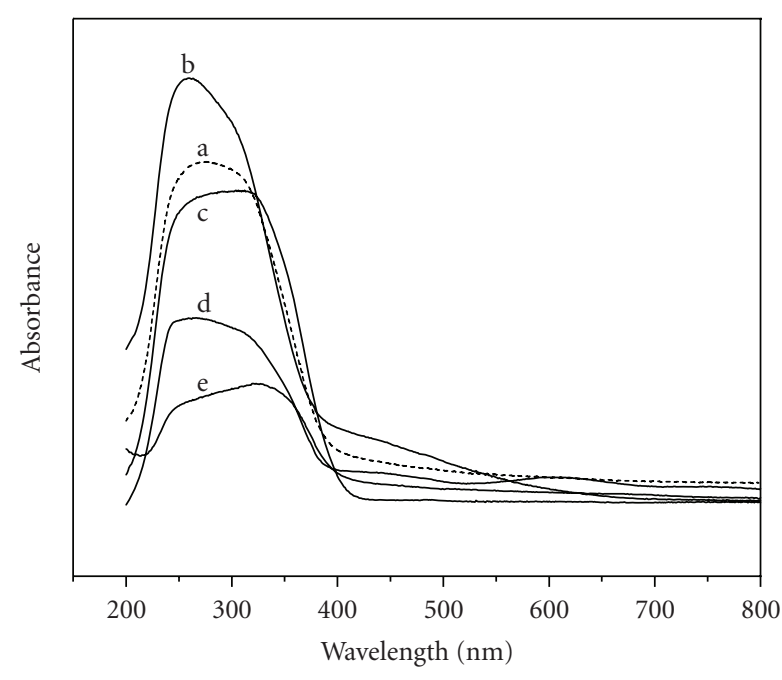

(a)

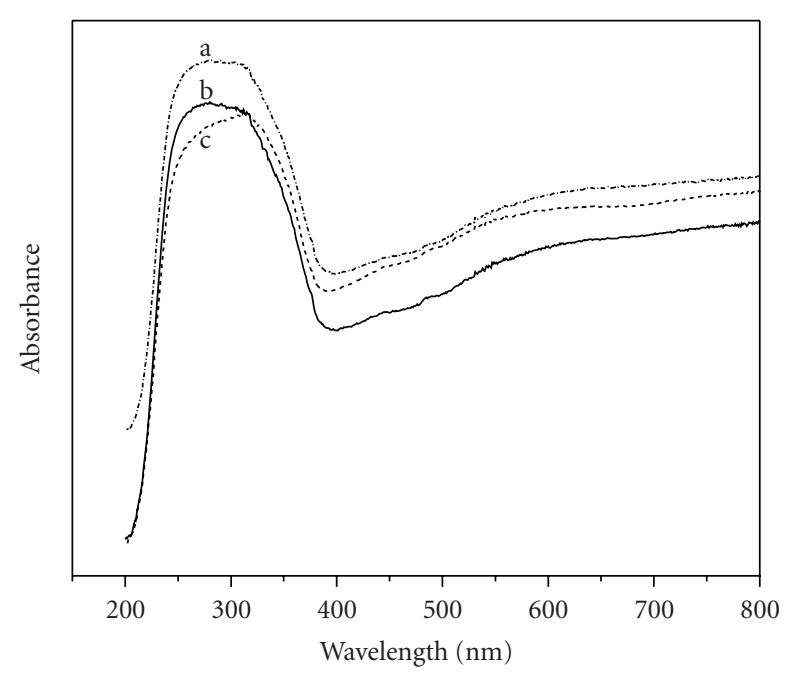

(b)

Figure 6: Diffuse reflectance UV-Vis spectra of (a) hydrothermally prepared $\mathrm{Au} / \mathrm{TiO}_{2}$ and $\mathrm{TiO}_{2}$ samples: (a) H2, (b) $\mathrm{H}$ 3, (c) H4, (d) $\mathrm{H}$, and (e) $\mathrm{T} 1$, and (b) impregnation-prepared $\mathrm{Au} / \mathrm{TiO}_{2}$ samples: (a) I1, (b) I2, and (c) I3.

acetone in reactant mixture, and the pore characteristics of the catalyst samples. The presence of gold also resulted in considerable enhancement of the activity of a catalyst, where both the content and the size of Au particles played an important role. The highlights of these results are presented below.

\subsection{1. $\mathrm{TiO}_{2}$}

Curves (a)-(c) in Figure 7 show the yield of $\mathrm{CO}_{2}$ as a function of UV irradiation, when a mixture of acetone and air, containing varying concentrations of acetone, was reacted over mesoporous $\mathrm{TiO}_{2}$ (sample T1). As seen in these data, yield of $\mathrm{CO}_{2}$ corresponds to $100 \%$ conversion for acetone concentration of $2.7 \mathrm{~mol} \%$ or less, the value of $t_{1 / 2}$ (time taken for $50 \%$ conversion of acetone) being around $30 \mathrm{~min}$ utes (curve (a)). The yield of $\mathrm{CO}_{2}$ decreased progressively along with the simultaneous formation of other reaction products for increasing acetone: air mol ratios in the reaction mixture. For instance, in the case of acetone concentration at $10 \mathrm{~mol} \%$, conversion to $\mathrm{CO}_{2}$ was limited to $\sim 25 \%$ even after $\sim 2$ hours of reaction time (curve (c)). As mentioned above, ethane and methyl formate were the other reaction products formed for higher molar concentrations of acetone in air, as detected in the GC-MS analysis of reaction products. Curve (d) in Figure 7 shows the representative data on ethane yield for the experiment carried out with $13 \mathrm{~mol} \%$ of acetone in air. The yields of methyl formate and water formed in the reaction were not very reproducible because of their condensing nature, and no attempt is therefore made to compile the quantitative data on these products.

\subsection{2. $\mathrm{Au} / \mathrm{TiO}_{2}$}

The reaction rate was much higher in the case of gold containing $\mathrm{TiO}_{2}$ samples, with the activity depending upon the

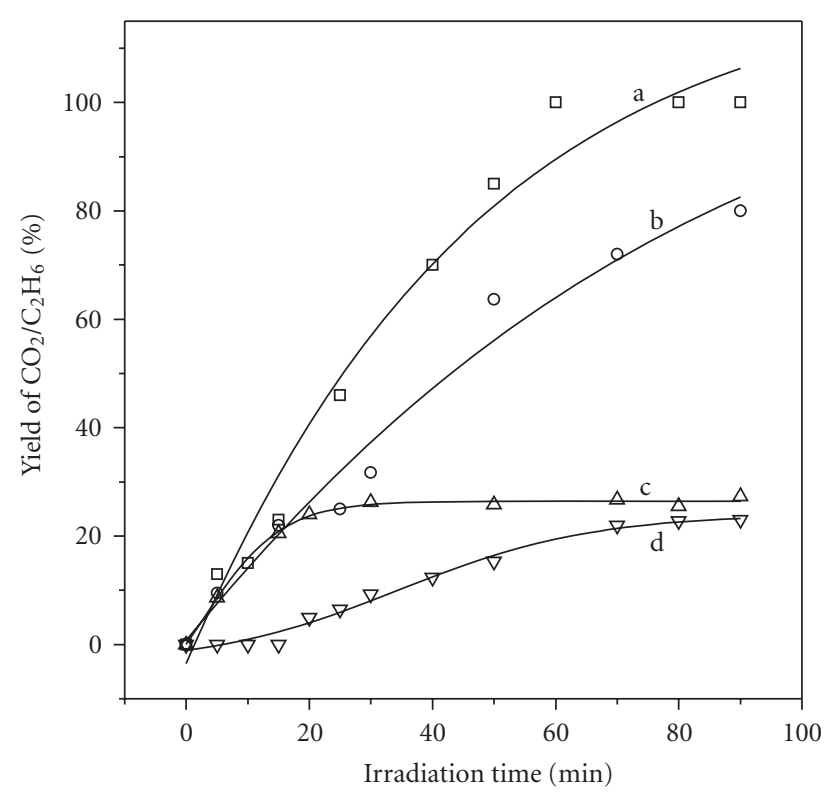

Figure 7: Yield of $\mathrm{CO}_{2}$ (curves (a)-(c)) and $\mathrm{C}_{2} \mathrm{H}_{6}$ (curve (d)) as a function of time, when mesoporous $\mathrm{TiO}_{2}$ (sample T1) was used for the UV-induced vapor-phase photocatalytic oxidation of acetone present at varying concentrations in air. (a) 2.7, (b) 5.3, (c) 10, and (d) $13 \mathrm{~mol} \%$.

gold content and the morphology of $\mathrm{TiO}_{2}$. Figure 8 presents the yield of $\mathrm{CO}_{2}$ during photo-oxidation of acetone as a function of irradiation time for the experiments conducted on hydrothermally prepared sample $\mathrm{H} 3$ and for the different compositions of reactant mixture. As seen in the results of curves (a)-(c) in Figure 8, not only the conversion but the rate of the reaction also depended upon acetone concentration, the lower the concentration the faster being the reaction, as expected. Lower conversions were observed for the 


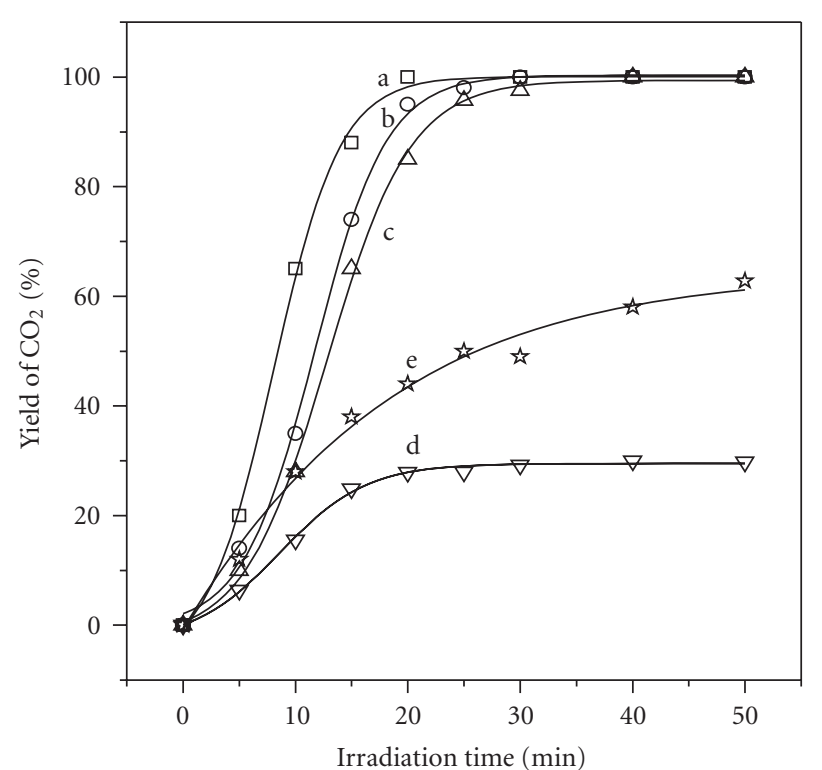

FIGURE 8: Yield of $\mathrm{CO}_{2}$ as a function of UV-radiation dose when hydrothermally synthesized $\mathrm{Au} / \mathrm{TiO}_{2}$ catalyst $\mathrm{H} 3$ (curves (a)-(d)) and H4 (curve (e)) were employed for vapor-phase photo-oxidation of acetone present at different concentrations in air. (a) 1.1, (b) 2.5, (c) 4.8, (d) 13, and (e) $3.9 \mathrm{~mol} \%$.

reaction mixture containing a higher concentration of acetone (Figure 8, curve (d)), along with the formation of other reaction products as in the case of $\mathrm{TiO}_{2}$.

Calcination of a sample at higher temperatures resulted in considerable loss of catalytic activity. Comparative data on reaction of acetone $(3.9 \mathrm{~mol} \%)+$ air over sample $\mathrm{H} 4$, that is sample calcined at $773 \mathrm{~K}$ instead of $623 \mathrm{~K}$ (sample H3), are shown in curve (e) of Figure 8. As seen in Figure 8 curve (e), less than $60 \%$ of acetone gets converted to $\mathrm{CO}_{2}$ in this case, even for a lower concentration of acetone in air. These results show a strong relationship between the catalytic activity, surface area, and the size of gold particles, which are affected considerably on calcination.

$\mathrm{Au} / \mathrm{TiO}_{2}$ samples $\mathrm{H} 5$ and $\mathrm{H} 6$, with a higher gold content of 0.8 and $1.3 \mathrm{wt} \%$, respectively (see Table 1 ), showed lower catalytic activity as compared to sample $\mathrm{H} 3$ containing $\sim 0.6 \mathrm{wt} \% \mathrm{Au}$. For instance, samples $\mathrm{H} 5$ and $\mathrm{H} 6$ gave rise to a maximum yield of $\mathrm{CO}_{2}$ at ca. $70 \%$ and $80 \%$, respectively, during the reaction of acetone $(3.5 \mathrm{~mol} \%)+$ air for about 80 minutes. Similarly, the samples synthesized by impregnation (I1-I3) showed lower catalytic activity in terms of reaction rate as compared to the corresponding hydrothermally synthesized samples. Figure 9 presents typical results on dosedependent $\mathrm{CO}_{2}$ yields for reaction of acetone $(\sim 3.4 \mathrm{~mol} \%)$ + air over samples I1-I3. A progressive increase in activity is observed as a function of gold content in these data. Thus, while almost $100 \%$ conversion of acetone was observed in case of samples containing 1.5 or $2 \mathrm{wt} \%$ of Au (curves (b) and (c)), sample I1 gave only ca. $60 \%$ conversion even after two hours of reaction time. At the same time, the value of $t$ $1 / 2$ is about 20 to 30 minutes in case of data in Figure 9 curves

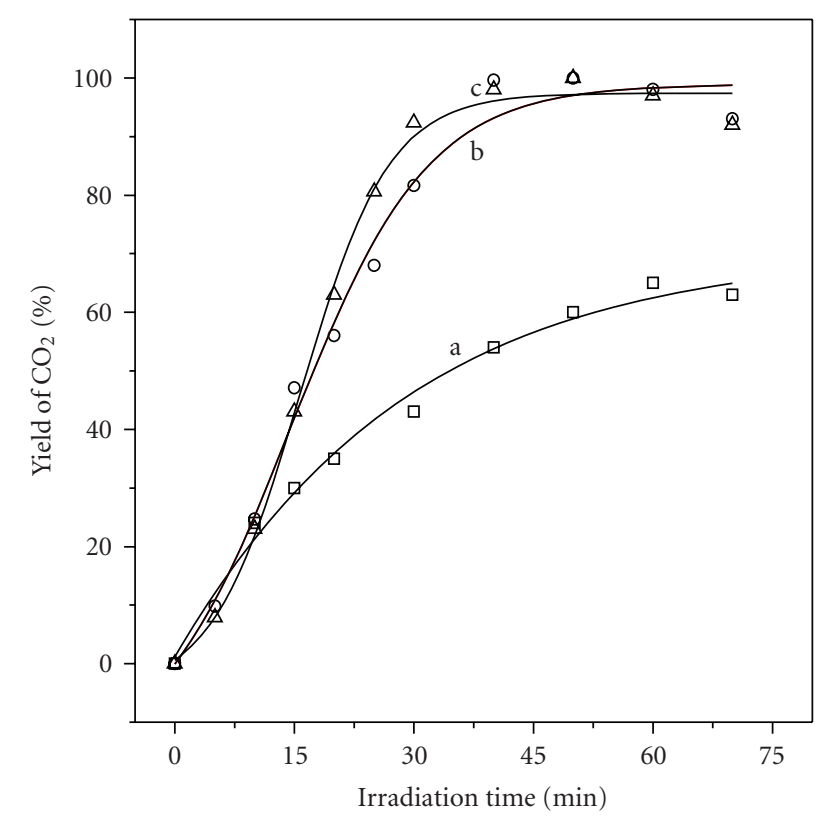

FIGURE 9: Yield of $\mathrm{CO}_{2}$ as a function of UV-radiation dose during the vapor-phase photo-oxidation of acetone, $(3.2-3.5 \mathrm{~mol} \%$ in air) at room temperature over impregnation-prepared $\mathrm{Au} / \mathrm{TiO}{ }_{2}$ samples I1 (curve (a)), I2 (curve (b)), and I3 (curve (c)).

(b) and (c), as compared to 8 to 13 minutes in case of sample H3 having lower gold content (Figure 8).

These results thus provide evidence that the activity of a catalyst is governed by multiple factors. In addition to surface area and gold content, morphology of $\mathrm{TiO}_{2}$ and the size of the gold particles also contribute significantly to the overall catalytic activity. The poorer activity of samples $\mathrm{H} 5$ and H6 as compared to H3 may be attributed to the increase in gold crystallite size with increasing gold content (TEM evidence). The extraordinary catalytic and optical properties of smaller-size $(<2 \mathrm{~nm})$ gold particles are now a wellreported phenomenon $[27,28]$. It is known that the gold catalysts are structure sensitive and the binding states of reactant molecules over Au nanoparticles dispersed over metal oxide supports are found to be different than those over bulk gold or gold films. It is suggested that the gold-metal oxide interfaces act as sites for the activation of molecules such as $\mathrm{O}_{2}, \mathrm{CO}$, hydrocarbons, and so forth [27]. In some of the studies, these unique properties of gold nanoparticles are attributed to their electronic structure [29]. We have demonstrated earlier that even a marginal increase in gold particle size as a result of high-temperature calcination may lead to a considerable decrease in the adsorption and catalytic activity of $\mathrm{Au} / \mathrm{Fe}_{2} \mathrm{O}_{3}$ catalysts [30].

\subsection{Infrared spectroscopy}

The results of our in situ DRIFT spectroscopy studies, where pure acetone vapor or acetone + air was dosed over representative catalyst samples after appropriate pretreatment, are presented in the following subsections. 


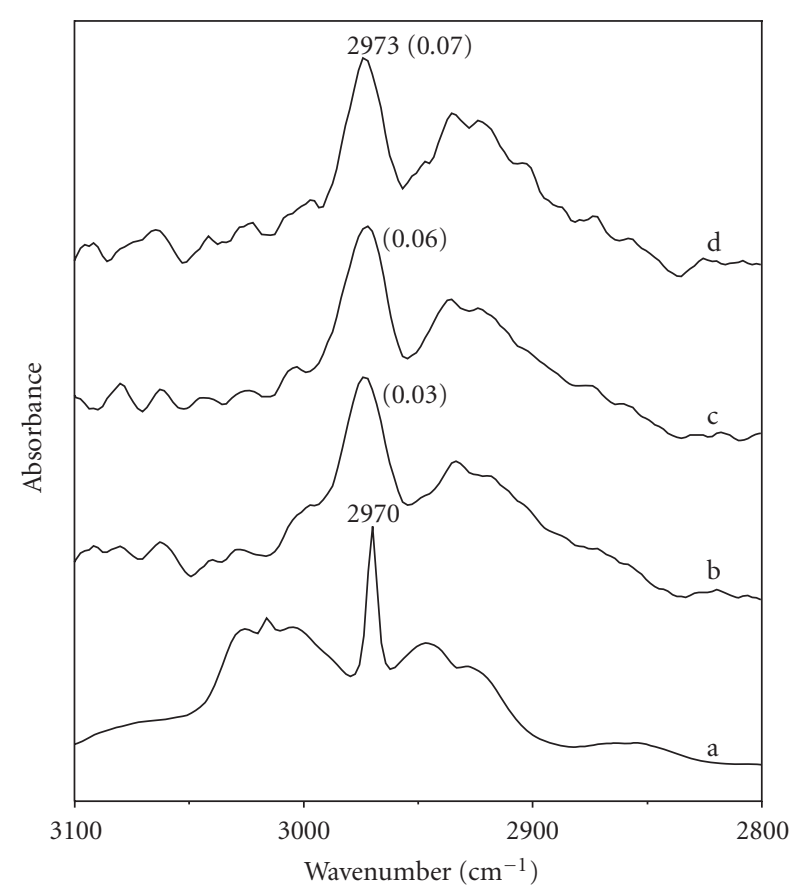

FIGURE 10: C-H stretching region infrared spectra of sample $\mathrm{H} 3$ (hydrothermally synthesized $\mathrm{Au} / \mathrm{TiO}_{2}$ ), exposed to $0.2 \mu \mathrm{mol}$ of acetone vapor and recorded after the lapse of 10 minutes (curve (b)) and subsequent heating at $320 \mathrm{~K}$ (curve (c)) and $360 \mathrm{~K}$ (curve (d)). Curve (a) shows corresponding vibrational bands of acetone vapor. The numbers given in the parentheses indicate the absorbance value of the particular IR band.

\subsubsection{Adsorption of acetone}

Curve (b) in Figure 10 exhibits the C-H stretching (3100$2800 \mathrm{~cm}^{-1}$ ) vibrational bands formed over hydrothermally prepared $\mathrm{Au} / \mathrm{TiO}_{2}$ sample $\mathrm{H} 3$ on exposure to $0.2 \mu \mathrm{molg} \mathrm{g}^{-1}$ of acetone at room temperature and recorded after the lapse of $\sim 10$ minutes. The intensity of this band remained unchanged when more amount of acetone (up to $\sim 1 \mu \mathrm{mol} \mathrm{g}^{-1}$ ) was dosed over the sample in form of successive pulses. Comparative IR spectrum recorded for acetone vapor in this region is shown in curve (a) of this figure. The $v(\mathrm{C}-\mathrm{H})$ bands of Figure 10(b) show the absence of Q-branch splitting of vibrational-rotational bands associated with acetone vapor (curve (a)). Also, instead of a sharp band at $2970 \mathrm{~cm}^{-1}$ (band width $\sim 5 \mathrm{~cm}^{-1}$ ) in case of acetone vapor (curve (a)), we observe a considerably broadened band at $2973 \mathrm{~cm}^{-1}$, the corresponding value of band width (full width at half maximum, FWHM) being $\sim 18 \mathrm{~cm}^{-1}$ for acetone in its adsorbed state (curve (b)). This band was found to be quite stable on thermal activation, as seen from the relative absorbance values in spectra (c) and (d) of Figure 10, recorded on rise in sample temperature to $320 \mathrm{~K}$ and $360 \mathrm{~K}$ subsequent to saturation coverage. The intensity of this band decreased only marginally even after raising the sample temperature to $470 \mathrm{~K}$.

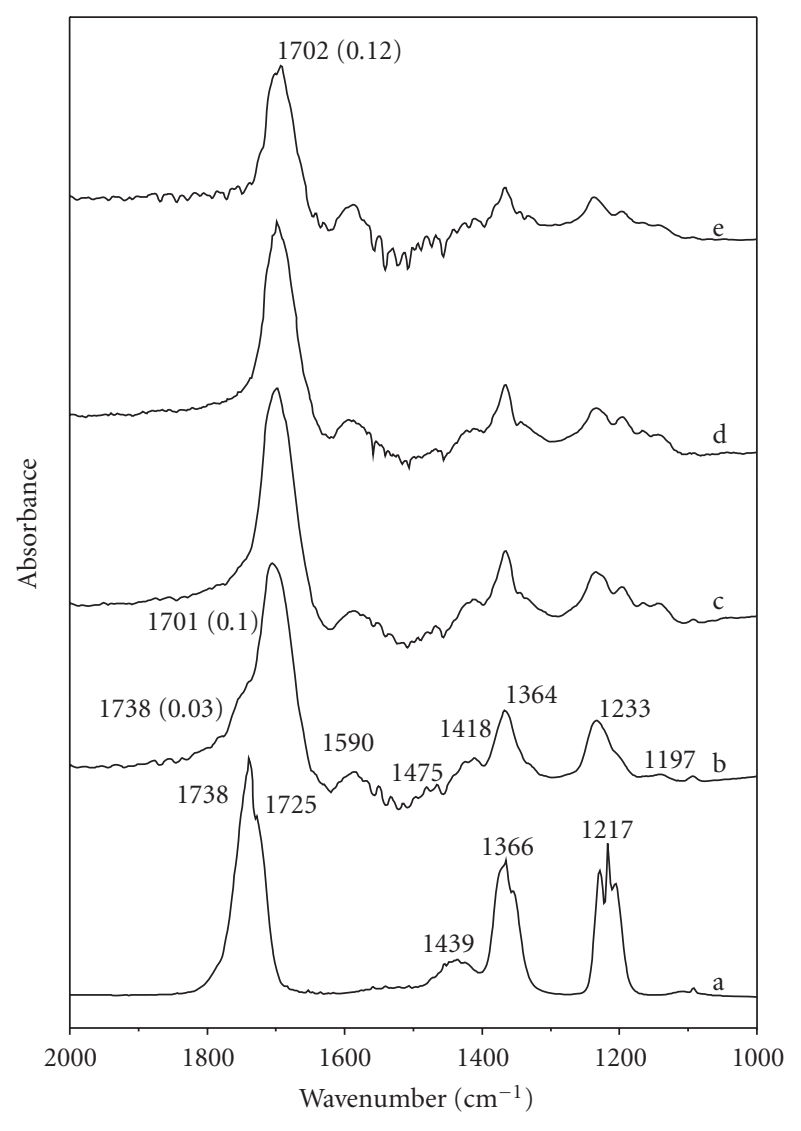

Figure 11: Stretching $\mathrm{C}=\mathrm{O}, \mathrm{C}=\mathrm{C}, \mathrm{C}-\mathrm{C}$, and deformation $\mathrm{CH}$ region vibrational bands developed on sample $\mathrm{H} 3$ after exposure to $0.2 \mu \mathrm{mol}\left(14 \mu \mathrm{mol} \mathrm{g}^{-1}\right)$ of acetone vapor and recorded after a delay time of 2 minutes (curve (b)) and 15 minutes (curve (c)) and subsequent raising of sample temperature to $320 \mathrm{~K}$ (curve (d)) and $360 \mathrm{~K}$ (curve (d)). Curve (a) shows corresponding vibrational bands of acetone vapor. The numbers given in the parentheses indicate the absorbance value of the particular IR band.

Figure 11 presents corresponding plots in 2000$1000 \mathrm{~cm}^{-1}$ region $(\nu \mathrm{C}=\mathrm{O}, \nu \mathrm{C}=\mathrm{C}, \nu \mathrm{C}-\mathrm{C}$, and $\delta \mathrm{CH}$ regions $)$. Curve (a) shows again a comparative spectrum of acetone vapor. In the $\mathrm{CO}$ stretching region, we observe a broad band centered at $\sim 1701 \mathrm{~cm}^{-1}$ and a shoulder band at $\sim 1738 \mathrm{~cm}^{-1}$ in curve (b) of Figure 11, recorded soon after adsorption of acetone over sample H3. Instead, a doublet at 1738 and $1725 \mathrm{~cm}^{-1}$ is observed in case of acetone vapor (curve (a)), arising due to the Fermi resonance between the fundamental $\mathrm{CO}$ vibration and an overtone. With an increase in contact time, the intensity of $1738 \mathrm{~cm}^{-1}$ band decreases further while the frequency of the new band formed at $1701 \mathrm{~cm}^{-1}$ shifts to a lower value of $1695 \mathrm{~cm}^{-1}$ (Figure 11, curve (c)). As in the case of $\mathrm{C}-\mathrm{H}$ stretching bands, the $v(\mathrm{CO})$ vibrational bands were found to be fairly stable on raising the sample temperature up to $470 \mathrm{~K}$ after acetone adsorption. Spectra (d) and (e) in Figure 11 show the representative plots obtained at sample temperatures of $320 \mathrm{~K}$ and $350 \mathrm{~K}$, respectively. 


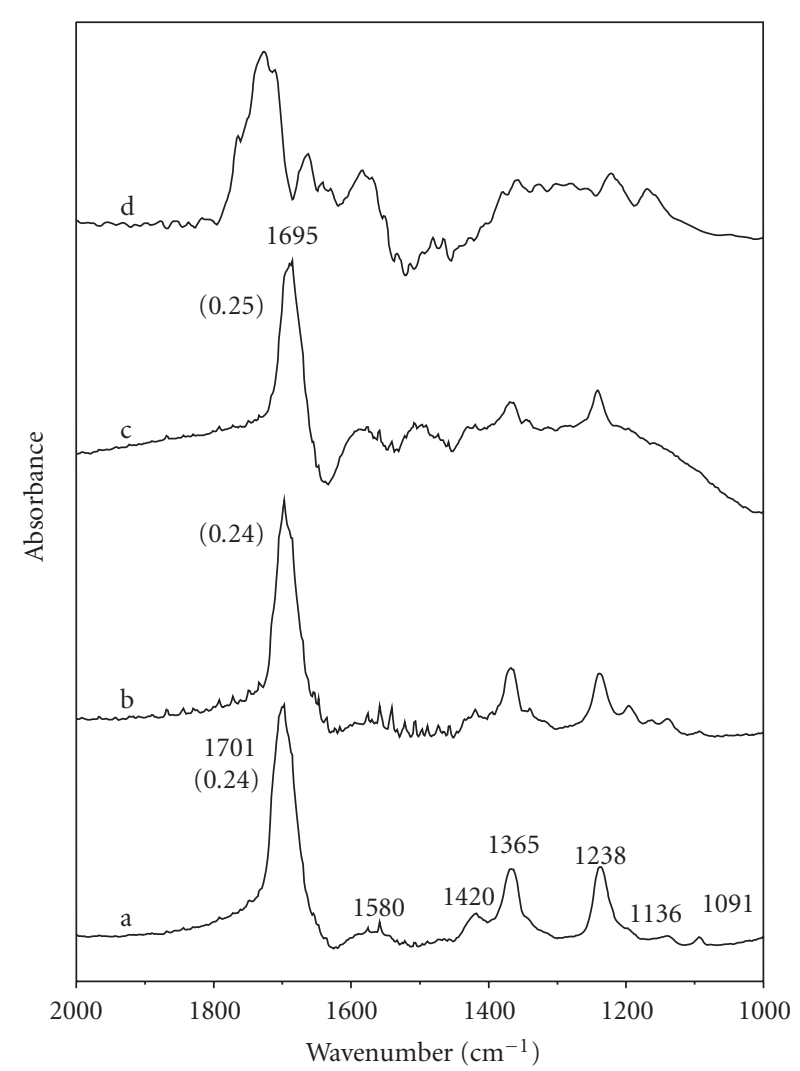

Figure 12: Stretching $\mathrm{C}=\mathrm{O}, \mathrm{C}=\mathrm{C}, \mathrm{C}-\mathrm{C}$, and deformation $\mathrm{CH}$ region vibrational bands developed on sample $\mathrm{H} 3$ after exposure to acetone vapor + air and recorded after a delay time of $10 \mathrm{~min}$ utes (curve (a)) and on subsequent raising of sample temperature to $320 \mathrm{~K}$ (curve (b)) and $370 \mathrm{~K}$ (curve (c)). Curve (d) shows comparative vibrational bands of methyl formate vapor adsorbed over $\mathrm{H} 3$ under nitrogen flow at room temperature. The numbers given in the parentheses indicate the absorbance value of the particular IR band.

\subsubsection{Adsorption of acetone + air}

The vibrational bands similar to those in Figures 10 and 11 were observed on interaction of acetone $(10 \mathrm{~mol} \%)+$ air at room temperature, the only difference being a considerable increase in the intensity of the bands. Figure 12 exhibits IR spectra of $\mathrm{H} 3$ sample at saturation coverage, recorded 10 minutes after exposure (curve (a)) and after subsequent rise in sample temperature to 320 (curve (b)) and $350 \mathrm{~K}$ (curve (c)). As seen from the absorbance values given in Figure 12, the intensity of the vibrational bands in these spectra is greater by a factor of almost 2 , compared to the corresponding experiments performed using acetone alone (Figure 11). These results indicate that the presence of oxygen facilitated the reaction of acetone over catalyst surface to form certain strongly adsorbed and thermally stable species (Figures 12(curve (b)), 12(curve (C))). We may also mention that the spectral features similar to those in Figures 10, 11, and 12 were observed in the case of impregnation-prepared $\mathrm{Au} / \mathrm{TiO}_{2}$ samples having a different gold content.

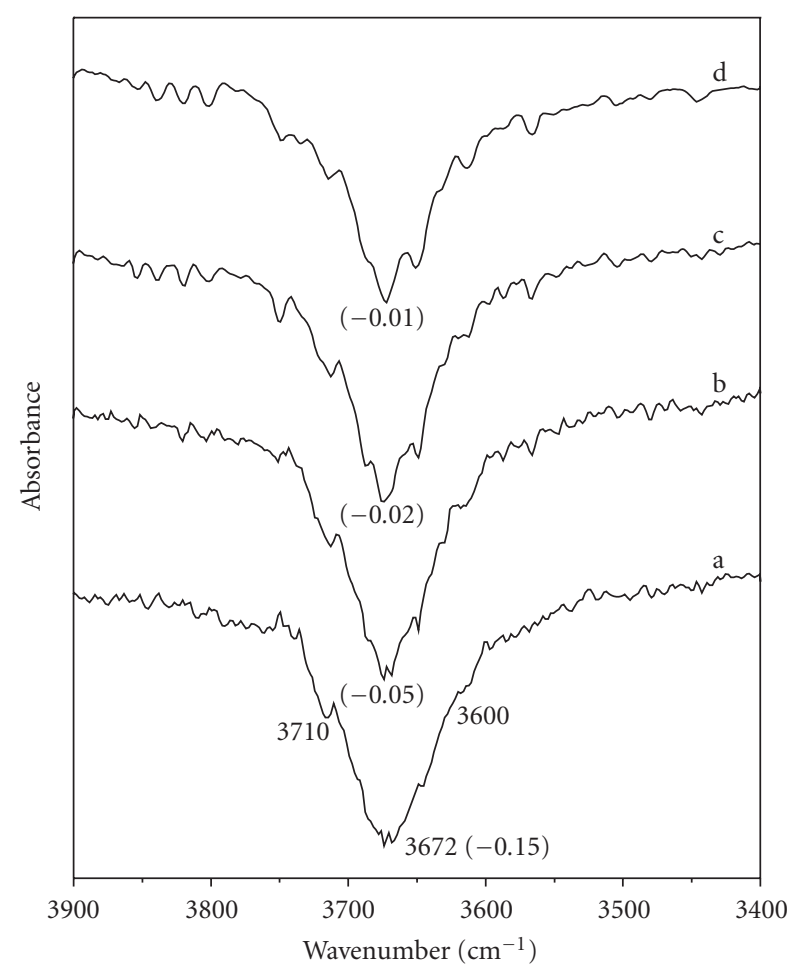

FIGURE 13: Hydroxyl region IR spectra of sample H3 after room temperature adsorption of $14 \mu \mathrm{mol} \mathrm{g}^{-1}$ of acetone vapor and recorded after the lapse of 15 minutes (curve (a)) and subsequent heating at $320 \mathrm{~K}$ (curve (b)), $350 \mathrm{~K}$ (curve (c)), and $380 \mathrm{~K}$ (curve (d)). The numbers given in the parentheses indicate the absorbance value of the particular IR band.

Adsorption of acetone over $\mathrm{TiO}_{2}$ gave rise to the vibrational bands similar again to those shown in Figures 10 and 11, described above. The IR bands were found to be quite stable on heating of the sample up to $470 \mathrm{~K}$ under nitrogen flow, as in the case of results obtained using $\mathrm{Au} / \mathrm{TiO}_{2}$.

\subsubsection{Hydroxyl region bands}

Curve (a) in Figure 13 presents the hydroxyl region bands of $\mathrm{Au} / \mathrm{TiO}_{2}$ (sample $\mathrm{H} 3$ ), exposed to $0.2 \mu \mathrm{mol} \mathrm{g}^{-1}$ of acetone and recorded soon after. As seen in this figure, the spectral developments in $v(\mathrm{CH})$ or $v(\mathrm{CO})$ regions are accompanied with simultaneous removal of IR bands of different hydroxyl groups at titania surface, as indicated by the negative absorbance values (peaks pointing downwards) of $v(\mathrm{OH})$ bands at 3710,3672 , and $3600 \mathrm{~cm}^{-1}$ in Figure 13. The presence of overlapping multiple vibrational bands in 3900$3400 \mathrm{~cm}^{-1}$ region, representing differently coordinated hydroxyl groups over the titania surface, has been reported earlier [31]. These results reveal a strong adsorbent-adsorbate interaction involving the hydroxyl groups, irrespective of their coordinative environment.

Based upon the above-mentioned information about the shape, width, and intensity, the IR absorption bands in Figures 10 and 11 may be attributed to an overlap of closely spaced vibrational bands, arising due to multiple adsorbed 
species. In some of the previously reported studies [32, 33], acetone is found to adsorb in molecular state over $\mathrm{TiO}_{2}$ at a lower coverage while at a higher coverage it undergoes an Aldol condensation reaction followed by dehydration to yield 4-methyl-3-penten-2-one $\left(\left(\mathrm{CH}_{3}\right)_{2} \mathrm{C}=\mathrm{CHCOCH}_{3}\right)$, commonly known as mesityl oxide (MSO). The absence of Q-branch splitting and broadening of the $v(\mathrm{C}-\mathrm{H})$ band shown in Figure 10 is in conformity with the presence of a condensed state of acetone. The IR absorption bands appearing at 2973 and $2931 \mathrm{~cm}^{-1}$ in Figure 10 and at 1702, 1475, and $1364 \mathrm{~cm}^{-1}$ in Figure 11 may be assigned to this strongly adsorbed state of acetone molecules (cf. Figures 10 and 11, curve (a)). The presence of a weak shoulder at $1738 \mathrm{~cm}^{-1}$ in Figure 11 (curve b) and its removal with increase in contact time (curve c) indicate that the transformation of acetone vapor to its condensed state is a slow and activated process. We, however, observe no formation of MSO, both for adsorption of acetone alone or acetone + air. As mentioned by Zaki et al. [33], the mesityl oxide is distinguishable from acetone by a $\nu \mathrm{C}=\mathrm{C}$ band at $1634 \mathrm{~cm}^{-1}$ and $\nu \mathrm{C}-\mathrm{C}$ band at $1294 \mathrm{~cm}^{-1}$. No such bands are, however, observed in Figures 11 and 12, thus ruling out the formation of MSO under experimental conditions of this study.

The $\nu\left(\mathrm{CH}_{3}\right)$ vibration at $2973 \mathrm{~cm}^{-1}$ (Figure 10), $\nu \mathrm{C}=\mathrm{O}$ vibration at $1695 \mathrm{~cm}^{-1}$, and several weak absorption bands in $1900-1100 \mathrm{~cm}^{-1}$ region (Figure 12) may be assigned to methyl formate (methyl methanoate) in its adsorbed state, as reported in one of our earlier studies [15]. This identification is validated by a study of Lochař et al. [34] where similar bands were observed for adsorption of methyl formate over metal oxide surfaces. To further confirm the assignment of absorption bands in Figures 11 and 12, methyl formate vapor was dosed over sample $\mathrm{H} 3$ at room temperature and the representative spectrum thus obtained is shown in curve (d) of Figure 12, which matches well with the IR bands shown in Figures 11 and 12 (curves (a)-(c)). We may also mention that the formation of methyl formate was detected clearly in our GC-MS analysis of reaction products formed in photo-oxidation of acetone over $\mathrm{TiO}_{2}$. A difference in the relative intensity and the shift in frequency of some of the bands in curves (c) and (d) of Figure 12 may be attributed to the difference in the binding of methyl formate groups, formed in situ and that adsorbed in a molecular form. We may also mention that the $v_{\text {as }}(\mathrm{COO})+\delta(\mathrm{CH})$ combination bands of adsorbed mono- and bidentate formate $\left(\mathrm{HCOO}^{-}\right)$species give rise to absorption bands at $2970 \mathrm{~cm}^{-1}$ and $2936 \mathrm{~cm}^{-1}$ whereas corresponding $\nu(\mathrm{CH})$ vibrations appear at $2896 \mathrm{~cm}^{-1}$ and $2856 \mathrm{~cm}^{-1}$. Similarly, in the lower IR region, the bands at $1575 \mathrm{~cm}^{-1}$ and $1376 \mathrm{~cm}^{-1}$ are assigned to $v_{\mathrm{as}}(\mathrm{COO})$ and $v_{\mathrm{s}}(\mathrm{COO})$ vibrations of the bidentate formate species while the bands at $1542 \mathrm{~cm}^{-1}$ and $1363 \mathrm{~cm}^{-1}$ arise due to such vibrations of monodentate formate species [15, 35-38]. A considerable increase of absorbance in 2950$2850 \mathrm{~cm}^{-1}$ region and a large width of $2973 \mathrm{~cm}^{-1}$ band in Figure 10, and similarly the presence of various unresolved overlapping bands in $1800-1000 \mathrm{~cm}^{-1}$ region (Figures 11 and 12), help us to conclude that in addition to methyl formate, $\mathrm{HCOO}^{-}$species may also form on interaction of acetone and subsequent thermal activation.
The active role of formate and methyl formate groups in photocatalytic reactions over titania and other oxide surfaces has been amply demonstrated by several research groups $[15,32,33,38,39]$. For instance, Wu et al. [39] demonstrated that the methoxy-, ethoxy-, and formate-type surface groups are photo-oxidized on $\mathrm{TiO}_{2}$ under UV-illumination, and the rate of photo-oxidation depends on the binding mode of these species at catalyst surface, the monodentate species being more reactive as compared to their bidentate counterparts. Simultaneous FTIR and photocatalysis studies conducted in our laboratory have also exhibited the involvement of such adsorbed species in the photo-oxidation of methanol over $\mathrm{TiO}_{2} / \mathrm{MCM}$ and $\mathrm{UO}_{x} / \mathrm{MCM}$ catalyst surfaces [15, 38]. El-Maazawi et al. [32] proposed a reaction mechanism, where formation of $\mathrm{O}^{-}$(ads) species from gasphase $\mathrm{O}_{2}$ and its reaction with adsorbed acetone are shown to play an important role.

To summarize, the results of our study reveal that the adsorption of acetone over nanostructured $\mathrm{TiO}_{2}$ or $\mathrm{Au} / \mathrm{TiO}_{2}$ may occur in several modes, giving rise to a condensed and strongly adsorbed state of molecular acetone and methyl formate and formate types of surface adsorbed species. The IR results show that the host matrix and the gold particles may serve as independent adsorption and reaction sites for acetone and oxygen molecules. Since similar IR absorbance bands are observed on adsorption over $\mathrm{TiO}_{2}$ and $\mathrm{Au} / \mathrm{TiO}_{2}$ and also with or without the presence of air in reaction mixture, it is apparent that the adsorption of acetone occurs primarily at titania surface. The spectral features in $v(\mathrm{OH})$ region (Figure 13) reveal that the $\mathrm{Ti}-\mathrm{OH}$ groups may directly interact with acetone molecules. This process is reversed on thermal activation, as is apparent from the absorbance values shown in Figure 13 (curves (b)-(d)). Since acetone + air adsorption over $\mathrm{Au} / \mathrm{TiO}_{2}$ gave rise to higher intensity of the IR absorption bands, as described above, we may conclude that the adsorption and activation of $\mathrm{O}_{2}$ molecules at $\mathrm{Au}$ sites plays an important role. This phenomenon, promoted only by nanosize Au particles, explains the high catalytic activity of sample $\mathrm{H} 3$ as compared to other samples having higher gold content but larger-size crystallites.

The overall photocatalytic process would therefore involve the interaction of these primary adsorbed species with the electron-hole pair generated on band gap excitation of $\mathrm{TiO}_{2}$, giving rise to formation of various ion-radicals, free radicals, and surface bonded transient species. Various possible photochemical steps may subsequently prevail, leading thereby to the formation of different reaction products, as has been reported widely (see, e.g., [40]).

\section{CONCLUSIONS}

The results of the present study demonstrate that the structural and morphological properties of $\mathrm{Au} / \mathrm{TiO}_{2}$ have a direct relationship with the activity of these photocatalysts. The role of a noble metal cocatalyst in semiconductor mediated photo-oxidation of organic compounds has been debated widely, and, in general, two different concepts have been accepted. According to the one theory, the enhancement of 
photocatalytic activity is attributable to an increase in charge separation efficiency, and the other is that the metal particles lead to the shift in quasi-Fermi level of the semiconductormetal composite to more negative potentials [41]. We observe no considerable shift in the UV-region absorbance band of $\mathrm{Au} / \mathrm{TiO}_{2}$ samples. Our IR spectroscopy results, on the other hand, suggest that the titania and gold particles serve as independent adsorption and reaction sites for acetone and oxygen molecules. Acetone molecules adsorb exclusively at $\mathrm{TiO}_{2}$ surface, giving rise to a condensed state as well as to the formation of formate- and methyl formate-type surface species. Based on the dependence of catalytic activity on gold particle size, we may infer that the Au sites are primarily responsible for the adsorption and activation of oxygen molecules. This is in agreement with the well-reported adsorption properties of small-size $(<2 \mathrm{~nm})$ gold particles at $\mathrm{Au} /$ support interfaces, as discussed above. Since our $\mathrm{Au} / \mathrm{TiO}_{2}$ samples showed no activity under visible light irradiation, it is evident that the direct absorption of radiation by gold particles as seen in Figure 6 may play an insignificant role. The band gap absorbance in $\mathrm{TiO}_{2}$ resulting in the generation of $\mathrm{e}^{-} / \mathrm{h}^{+}$pair may therefore solely govern the photochemical steps. Overall, the increase in the exposed active surface sites $\left(\mathrm{TiO}_{2}\right.$ and $\left.\mathrm{Au}\right)$ may influence both the chemisorption of the reactant molecules and the utilization efficiency of the photoinduced electron-hole pair.

\section{ACKNOWLEDGMENTS}

N. M. Gupta thanks the Council of Scientific and Industrial Research (CSIR), New Delhi, for a research grant under the Emeritus Scientist scheme. Authors thank Mr. Mahesh Kadgaonkar for help in the manuscript preparation. The help of Dr. Renu Pasricha and Dr. K. R. Patil in TEM and XPS studies is also acknowledged.

\section{REFERENCES}

[1] Q. Sheng, S. Yuan, J. Zhang, and F. Chen, "Synthesis of mesoporous titania with high photocatalytic activity by nanocrystalline particle assembly," Microporous and Mesoporous Materials, vol. 87, no. 3, pp. 177-184, 2006.

[2] J. Yu, Y. Su, B. Cheng, and M. Zhou, "Effects of $\mathrm{p}^{\mathrm{H}}$ on the microstructures and photocatalytic activity of mesoporous nanocrystalline titania powders prepared via hydrothermal method," Journal of Molecular Catalysis A, vol. 258, no. 1-2, pp. 104-112, 2006.

[3] A. J. Maira, K. L. Yeung, C. Y. Lee, P. L. Yue, and C. K. Chan, "Size effects in gas-phase photo-oxidation of trichloroethylene using nanometer-sized $\mathrm{TiO}_{2}$ catalysts," Journal of Catalysis, vol. 192, no. 1, pp. 185-196, 2000.

[4] K. L. Yeung, S. T. Yau, A. J. Maira, J. M. Coronado, J. Soria, and P. L. Yue, "The influence of surface properties on the photocatalytic activity of nanostructured $\mathrm{TiO}_{2}$," Journal of Catalysis, vol. 219, no. 1, pp. 107-116, 2003.

[5] H. Hayashi and K. Torii, "Hydrothermal synthesis of titania photocatalyst under subcritical and supercritical water conditions," Journal of Materials Chemistry, vol. 12, no. 12, pp. 3671-3676, 2002.
[6] Y.-F. Chen, C.-Y. Lee, M.-Y. Yeng, and H.-T. Chiu, "Preparing titanium oxide with various morphologies," Materials Chemistry and Physics, vol. 81, no. 1, pp. 39-44, 2003.

[7] J.-Y. Zheng, J.-B. Pang, K.-Y. Qiu, and Y. Wei, "Synthesis and characterization of mesoporous titania and silica-titania materials by urea templated sol-gel reactions," Microporous and Mesoporous Materials, vol. 49, no. 1-3, pp. 189-195, 2001.

[8] J.-H. Lee, I.-C. Leu, M.-C. Hsu, Y.-W. Chung, and M.-H. Hon, "Fabrication of aligned $\mathrm{TiO}_{2}$ one-dimensional nanostructured arrays using a one-step templating solution approach," Journal of Physical Chemistry B, vol. 109, no. 27, pp. 13056-13059, 2005.

[9] M. Anpo, S. Dohshi, M. Kitano, Y. Hu, M. Takeuchi, and M. Matsuoka, "The preparation and characterization of highly efficient titanium oxide-based photofunctional materials," Annual Review of Materials Research, vol. 35, pp. 1-27, 2005.

[10] J.-C. Xu, Y.-L. Shi, J.-E. Huang, B. Wang, and H.-L. Li, "Doping metal ions only onto the catalyst surface," Journal of Molecular Catalysis A, vol. 219, no. 2, pp. 351-355, 2004.

[11] S. Karvinen, "The effects of trace elements on the crystal properties of $\mathrm{TiO}_{2}$," Solid State Sciences, vol. 5, no. 5, pp. 811-819, 2003.

[12] C.-G. Wu, C.-C. Chao, and F.-T. Kuo, "Enhancement of the photo catalytic performance of $\mathrm{TiO}_{2}$ catalysts via transition metal modification," Catalysis Today, vol. 97, no. 2-3, pp. 103112, 2004.

[13] F. B. Li and X. Z. Li, "Photocatalytic properties of gold/gold ion-modified titanium dioxide for wastewater treatment," Applied Catalysis A, vol. 228, no. 1-2, pp. 15-27, 2002.

[14] K. Bhattacharya, A. K. Tripathi, G. K. Dey, and N. M. Gupta, "Vapor-phase photo-oxidation of methanol over nanosize titanium dioxide clusters dispersed in MCM-41 host material part 1: synthesis and characterization," Journal of Nanoscience and Nanotechnology, vol. 5, no. 5, pp. 790-796, 2005.

[15] K. Bhattacharyya, S. Varma, D. Kumar, A. K. Tripathi, and N. M. Gupta, "Vapor-phase photo-oxidation of methanol over nanosize titanium dioxide clusters dispersed in MCM-41 host material part 2: catalytic properties and surface transient species," Journal of Nanoscience and Nanotechnology, vol. 5, no. 5, pp. 797-805, 2005.

[16] L. Davydov, E. P. Reddy, P. France, and P. G. Smirniotis, "Transition-metal-substituted titania-loaded MCM-41 as photocatalysts for the degradation of aqueous organics in visible light," Journal of Catalysis, vol. 203, no. 1, pp. 157-167, 2001.

[17] Y. Xu and C. H. Langford, "Photoactivity of titanium dioxide supported on MCM41, zeolite X, and zeolite Y," Journal of Physical Chemistry B, vol. 101, no. 16, pp. 3115-3121, 1997.

[18] R. Asahi, T. Morikawa, T. Ohwaki, K. Aoki, and Y. Taga, "Visible-light photocatalysis in nitrogen-doped titanium oxides," Science, vol. 293, no. 5528, pp. 269-271, 2001.

[19] G. Hitoki, T. Takata, J. N. Kondo, M. Hara, H. Kobayashi, and K. Domen, "An oxynitride, TaON, as an efficient water oxidation photocatalyst under visible light irradiation $(\lambda \leq$ 500 nm)," Chemical Communications, vol. 16, pp. 1698-1699, 2002.

[20] C. H. Rhee, S. W. Bae, and J. S. Lee, "Template-free hydrothermal synthesis of high surface area nitrogen-doped titania photocatalyst active under visible light," Chemistry Letters, vol. 34, no. 5, pp. 660-661, 2005.

[21] A. R. Gandhe, S. P. Naik, and J. B. Fernandes, "Selective synthesis of $\mathrm{N}$-doped mesoporous $\mathrm{TiO}_{2}$ phases having enhanced 
photocatalytic activity," Microporous and Mesoporous Materials, vol. 87, no. 2, pp. 103-109, 2005.

[22] W. Yen and Q. Kun-Yuan, "Nonsurfactant route to nanoporous phenyl-modified hybrid silica materials," in Nanoporous Materials: Science and Engineering, G. Q. Lu and X. S. Zhao, Eds., vol. 4 of Series on Chemical Engineering, p. 873, World Scientific, Singapore, 2004.

[23] E. L. Crepaldi, G. J. D. A. A. Soler-Illia, D. Grosso, F. Cagnol, F. Ribot, and C. Sanchez, "Controlled formation of highly organized mesoporous titania thin films: from mesostructured hybrids to mesoporous nanoanatase $\mathrm{TiO}_{2}$," Journal of the American Chemical Society, vol. 125, no. 32, pp. 9770-9786, 2003.

[24] Y. V. Kolen'ko, B. R. Churagulov, M. Kunst, L. Mazerolles, and C. Colbeau-Justin, "Photocatalytic properties of titania powders prepared by hydrothermal method," Applied Catalysis B, vol. 54, no. 1, pp. 51-58, 2004.

[25] X. Z. Li and F. B. Li, "Study of $A u / A u^{3+}-\mathrm{TiO}_{2}$ photocatalysts toward visible photooxidation for water and wastewater treatment," Environmental Science and Technology, vol. 35, no. 11, pp. 2381-2387, 2001.

[26] C.-M. Yang, M. Kalwei, F. Schüth, and K.-J. Chao, "Gold nanoparticles in SBA-15 showing catalytic activity in CO oxidation," Applied Catalysis A, vol. 254, no. 2, pp. 289-296, 2003.

[27] M. Haruta, "Size- and support-dependency in the catalysis of gold," Catalysis Today, vol. 36, no. 1, pp. 153-166, 1997.

[28] M. Valden, X. Lai, and D. W. Goodman, "Onset of catalytic activity of gold clusters on titania with the appearance of nonmetallic properties," Science, vol. 281, no. 5383, pp. 16471650, 1998.

[29] C. N. R. Rao, G. U. Kulkarni, P. John Thomas, and P. P. Edwards, "Size-dependent chemistry: properties of nanocrystals," Chemistry: A European Journal, vol. 8, no. 1, pp. 28-35, 2002.

[30] N. M. Gupta and A. K. Tripathi, "The role of nanosize gold particles in adsorption and oxidation of $\mathrm{CO}$ over $\mathrm{Au} / \mathrm{Fe}_{2} \mathrm{O}_{3}$ catalyst," Gold Bulletin, vol. 34, pp. 120-128, 2001.

[31] G. Busca, H. Saussey, O. Saur, J. C. Lavalley, and V. Lorenzelli, "FT-IR characterization of the surface acidity of different titanium dioxide anatase preparations," Applied Catalysis, vol. 14, pp. 245-260, 1985.

[32] M. El-Maazawi, A. N. Finken, A. B. Nair, and V. H. Grassian, "Adsorption and photocatalytic oxidation of acetone on $\mathrm{TiO}_{2}$ : an in situ transmission FT-IR study," Journal of Catalysis, vol. 191, no. 1, pp. 138-146, 2000.

[33] M. I. Zaki, M. A. Hasan, and L. Pasupulety, "Surface reactions of acetone on $\mathrm{Al}_{2} \mathrm{O}_{3}, \mathrm{TiO}_{2}, \mathrm{ZrO}_{2}$, and $\mathrm{CeO}_{2}$ : IR spectroscopic assessment of impacts of the surface acid-base properties," Langmuir, vol. 17, no. 3, pp. 768-774, 2001.

[34] V. Lochař, J. Machek, and J. Tichý, "Mechanism of selective oxidation of methanol over stannic oxide-molybdenum oxide catalyst," Applied Catalysis A, vol. 228, no. 1-2, pp. 95-101, 2002.

[35] G. Busca, A. S. Elmi, and P. Forzatti, "Mechanism of selective methanol oxidation over vanadium oxide-titanium oxide catalysts: a FT-IR and flow reactor study," Journal of Physical Chemistry, vol. 91, no. 20, pp. 5263-5269, 1987.

[36] I. A. Fisher and A. T. Bell, "A mechanistic study of methanol decomposition over $\mathrm{Cu} / \mathrm{SiO}_{2}, \mathrm{ZrO}_{2} / \mathrm{SiO}_{2}$, and $\mathrm{Cu} / \mathrm{ZrO}_{2} / \mathrm{SiO}_{2}$," Journal of Catalysis, vol. 184, no. 2, pp. 357-376, 1999.

[37] G. J. Millar, C. H. Rochester, and K. C. Waugh, "Infrared study of methyl formate and formaldehyde adsorption on re- duced and oxidised silica-supported copper catalysts," Journal of Chemical Society Faraday Transactions, vol. 87, pp. 27852793, 1991.

[38] D. Kumar, V. S. Kamble, and N. M. Gupta, "The role of nanosize particles of uranium oxide in the adsorption/reaction of methanol over $\mathrm{U}_{3} \mathrm{O}_{8} / \mathrm{MCM}-48$ : FTIR study," Catalysis Letters, vol. 88, no. 3-4, pp. 175-181, 2003.

[39] W.-C. Wu, C.-C. Chuang, and J.-L. Lin, "Bonding geometry and reactivity of methoxy and ethoxy groups adsorbed on powdered $\mathrm{TiO}_{2}$," Journal of Physical Chemistry B, vol. 104, no. 36, pp. 8719-8724, 2000.

[40] Z. Yu and S. S. C. Chuang, "In situ IR study of adsorbed species and photogenerated electrons during photocatalytic oxidation of ethanol on $\mathrm{TiO}_{2}$," Journal of Catalysis, vol. 246, no. 1, pp. 118-126, 2007.

[41] V. Subramanian, E. Wolf, and P. V. Kamat, "Semiconductormetal composite nanostructures. To what extent do metal nanoparticles improve the photocatalytic activity of $\mathrm{TiO}_{2}$ films?" Journal of Physical Chemistry B, vol. 105, no. 46, pp. 11439-11446, 2001. 


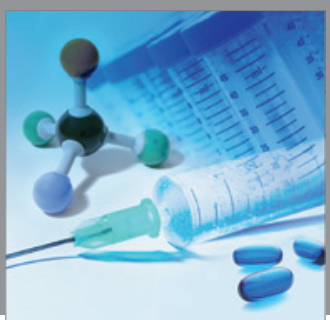

International Journal of

Medicinal Chemistry

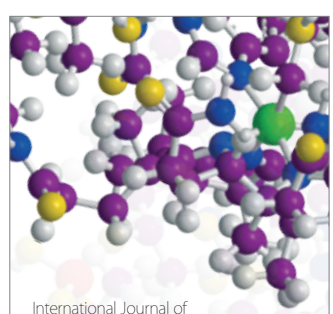

Carbohydrate Chemistry

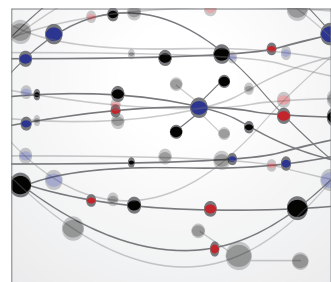

The Scientific World Journal
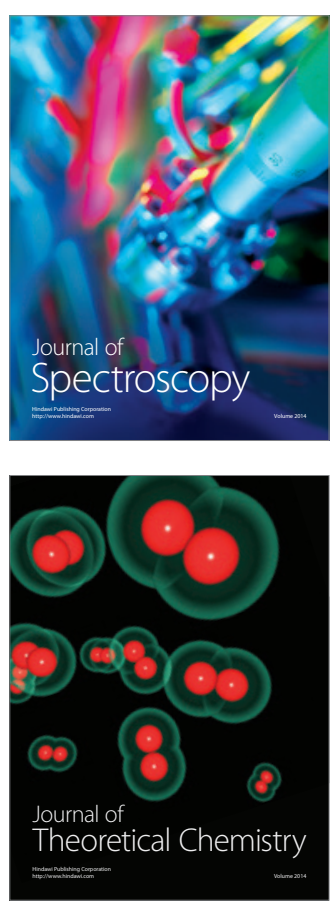
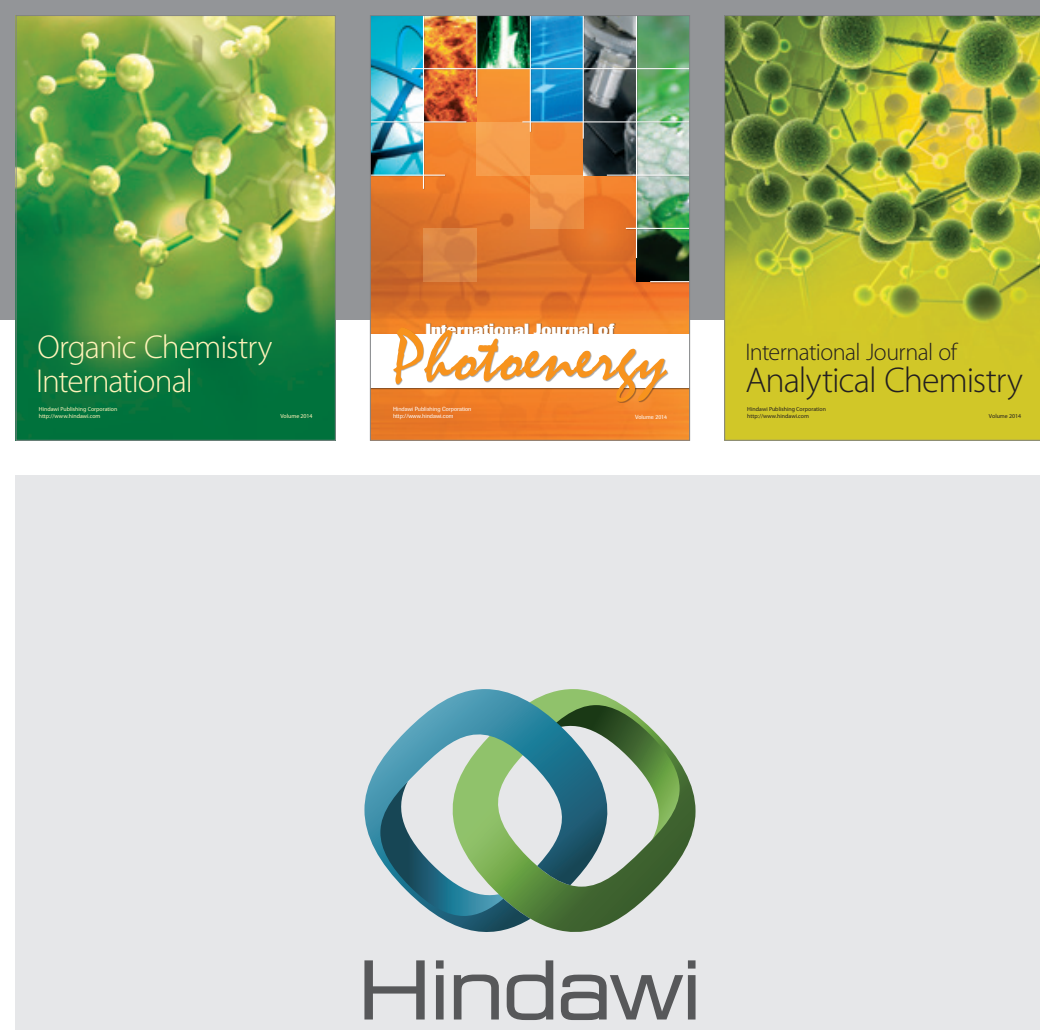

Submit your manuscripts at

http://www.hindawi.com
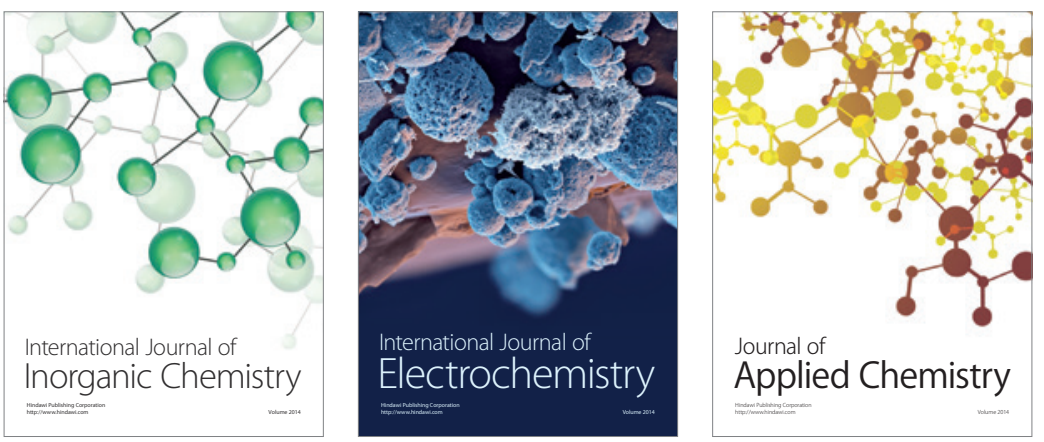

Journal of

Applied Chemistry
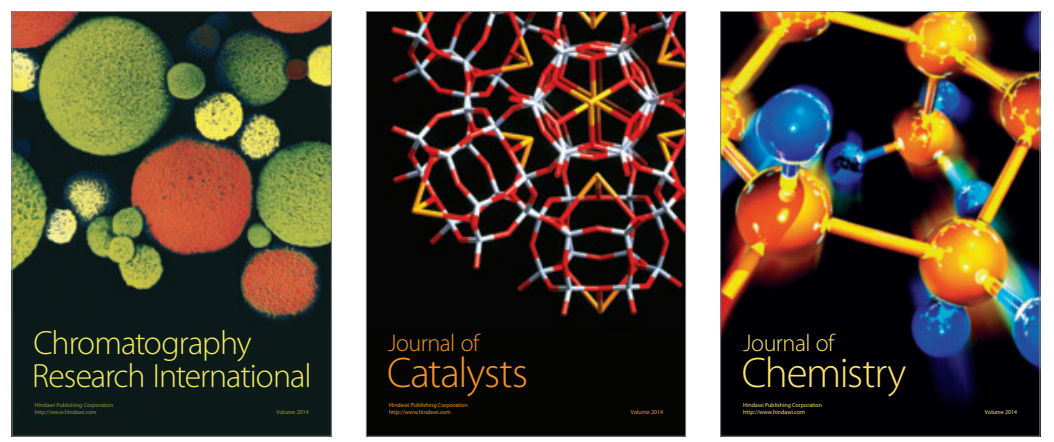
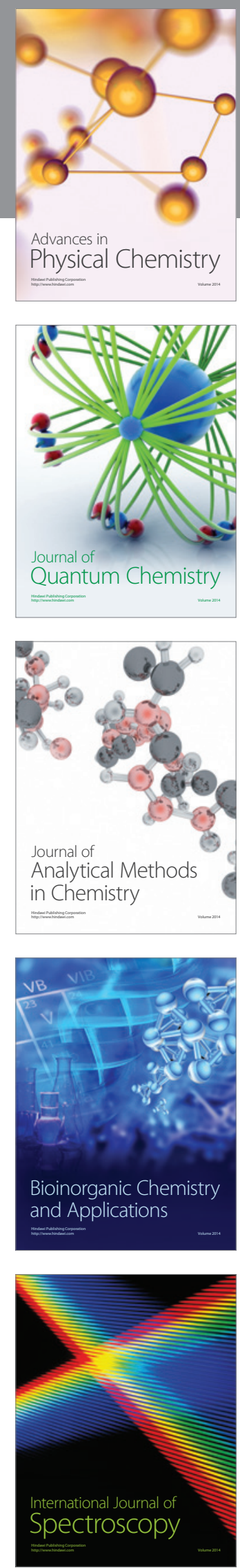